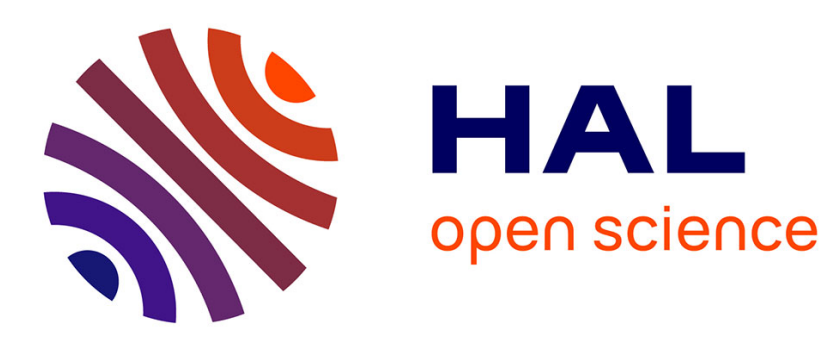

\title{
Effects of a crack on the stability of a non-linear rotor system
}

Jean-Jacques Sinou

\section{To cite this version:}

Jean-Jacques Sinou. Effects of a crack on the stability of a non-linear rotor system. International Journal of Non-Linear Mechanics, 2007, 42 (7), pp.959-972. 10.1016/j.ijnonlinmec.2007.04.002 . hal00213316

\section{HAL Id: hal-00213316 https://hal.science/hal-00213316}

Submitted on 23 Jan 2008

HAL is a multi-disciplinary open access archive for the deposit and dissemination of scientific research documents, whether they are published or not. The documents may come from teaching and research institutions in France or abroad, or from public or private research centers.
L'archive ouverte pluridisciplinaire HAL, est destinée au dépôt et à la diffusion de documents scientifiques de niveau recherche, publiés ou non, émanant des établissements d'enseignement et de recherche français ou étrangers, des laboratoires publics ou privés. 
Journal home page: http://www.sciencedirect.com/science/journal/00207462

Effects of a crack on the stability of a non-linear rotor system

International Journal of Non-Linear Mechanics, Volume 42, Issue 7, September 2007, Pages 959-972

Jean-Jacques Sinou

\title{
Effects of a crack on the stability of a non-linear rotor system
}

\author{
Jean-Jacques SINOU
}

Laboratoire de Tribologie et Dynamique des Systèmes UMR-CNRS 5513, Ecole Centrale de Lyon, 36 avenue Guy de Collongue, 69134 Ecully Cedex, France

\begin{abstract}
The stability of a rotor system presenting a transverse breathing crack is studied by considering the effects of crack depth, crack location and the shaft's rotational speed. The harmonic balance method, in combination with a path-following continuation procedure, is used to calculate the periodic response of a non-linear model of a cracked rotor system. The stability of the rotor's periodic movements is studied in the frequency domain by introducing the effects of a perturbation on the periodic solution for the cracked rotor system.

It is shown that the areas of instability increase considerably when the crack deepens, and that the crack's position and depth are the main factors affecting not only the non-linear behaviour of the rotor system but also the different zones of dynamic instability in the periodic solution for the cracked rotor. The effects of some other system parameters (including the disk position and the stiffness of the supports) on the dynamic stability of the non-linear periodic response of the cracked rotor system are also investigated.
\end{abstract}

Keywords: cracked rotor, non-linear vibration, harmonic balance method, stability analysis in the frequencydomain, rotating machinery.

\section{Introduction}

The influence of a transverse crack on the vibration of a rotating shaft has been at the focus of attention of many researchers. Extensive reviews of the dynamic response of cracked rotor systems were published by Wauer [1] and Dimarogonas [2]. Henry and Avae [3] indicated that the interaction between gravity and the crack excites resonances at main and sub critical speeds. They noted that the shaft executes respectively two or three loops per shaft revolution at the $\frac{1}{2}$ and $\frac{1}{3}$ sub-critical speeds. Finally, they pointed out that shaft imbalances may change the relative size of the loops. Gasch $[4,5]$ later demonstrated that opening and closing of the crack (referred to as the breathing effect) during its rotation is due mainly to the shaft's self-weight. He suggested that a slight decrease in the natural frequencies and the $2 \times$ harmonic components of the system in the frequency domain could be key indicators for the detection of 
transverse cracks in a rotating shaft. Mayes and Davies [6] analysed both experimentally and theoretically the effects of a tranverse crack in a rotor. They employed Green's functions to calculate the dynamic response of a cracked shaft and concluded that its non-linear response depends on the phase between the shaft's imbalance and the position of the crack. They also reported that at $\frac{1}{2}$ sub-critical speeds, the vibrational amplitude reaches a maximum when the crack is in phase with the shaft's imbalance, whereas it is minimised in the case of specific angular separations between the crack and the imbalance. In the latter case, traditional crack detection techniques could be rendered ineffective.

More recently, several researchers have studied the dynamic response of cracked rotors using theoretical or experimental methods alone, or by combining both approaches [7-15]. These studies highlight the possibility of rotor crack detection through the observation of the rotor's non-linear dynamic behaviour. The crack reduces the critical speed of the rotor system and produces changes in the amplitude of the $1 \times$, $2 \times$ and $3 \times$ vibrational harmonics. Depending on the size and location of the crack, the $1 \times, 2 \times$ and $3 \times$ amplitudes may increase or decrease: a slight increase in the crack depth may induced a strong increase in the $2 \times$ harmonic response. Consequently, the detection of variations in the shaft's orbital movements at one-half and one-third of the first critical speed can be used as a diagnostic tool.

Similarly, the influence of a single transverse crack on the stability of the periodic response of a rotor has been studied by various researchers [4,16-23]. As an example, Gasch [4] studied the influence of imbalance on the stability of a simple rotor with a transverse crack, and indicated that increased damping reduces the extent of the unstable region, whereas increased crack depth has the opposite effect. Moreover, the angle between the imbalance and the crack was shown to have an influence on the region of instability. Zhu et al. [22] demonstrated the presence of unstable regions near the rotational speeds of $\frac{1}{2} \times, 1 \times$, and $2 \times$ the critical speed, together with narrow regions of instability at lower speeds. They also indicated that a cracked rotor with high damping is normally stable, even when the crack depth increases. In order to determine the instability boundaries of a nonlinear cracked rotor system, the Floquet theory is generally used $[20,22,23]$. This approach requires the numerical calculation of the state transition matrix over a period of motion [20,22]. However, most existing studies that takes into account the stability of a cracked rotor system, only considers the first threshold speed limits and/or the first instability region beyond the first critical speed [23].

In the present paper, we propose to analyze and determine the non-linear response and the various regions of instability of a non-linear cracked rotor system, for the first three crtical speeds of the rotor. Moreover, in order to avoid the transition matrix computation associated with the Floquet method, the stability analysis is carried out in the frequency-domain, using a method in which a perturbation is applied to the known harmonic time-domain solution, which is calculated beforehand using the harmonic balance method.

The present paper is organised as follows: firstly, a description is provided of the rotor system, and of the method used to model and incorporate the crack, together with a breathing mechanism. Secondly, a brief explanation is given of the harmonic balance method, which is used to calculate the periodic response of the non-linear cracked rotor. The algorithm used to calculate the stability of these periodic solutions is then presented. Finally, the non-linear vibrational amplitudes of the cracked rotor are analysed. Numerical examples are presented, in which the influence on the stability of the non-linear periodic response of a cracked rotor system are determined as a function of crack depth, crack location, support stiffness and disc position.

\section{Model of the cracked rotor}

The layout of the cracked rotor system under consideration is shown in Figure 1. The rotor is composed of a shaft of radius $R$ and length $L$, with one disc of radius $R_{D}$ and thickness $h_{D}$ located at the mid-span. 
All values of the physical parameters are given in Table 1 .

\subsection{Equation of motion of the uncracked rotor}

Using a finite element method, the rotor is discretized into 10 Timoshenko beam finite elements, with four degrees of freedoms at each node [7]. The axial and torsional degrees of freedom are not considered here.

Each Timoshenko beam finite element has four degrees of freedom at each node :

$$
\left(\mathbf{M}_{T}^{e}+\mathbf{M}_{R}^{e}\right) \ddot{\mathbf{X}}^{e}+\left(\eta \mathbf{K}_{B}^{e}-\omega \mathbf{G}^{e}\right) \dot{\mathbf{X}}^{e}+\left(\mathbf{K}_{B}^{e}+\eta \omega \mathbf{K}_{C}^{e}\right) \mathbf{X}^{e}=\mathbf{F}^{e}
$$

where $\omega$ is the rotational speed. $\mathbf{M}_{T}^{e}$ and $\mathbf{M}_{R}^{e}$ are the translational and rotary mass matrices of the shaft element. $\mathbf{K}_{B}^{e}$ is the stiffness matrix and $\mathbf{K}_{C}^{e}$ the circulatory matrix which describes internal shaft damping. $\mathbf{G}^{e}$ is the gyroscopic matrix. $\eta$ defines the coefficient of damping, associated with modal damping, for the first mode of the system at rest $(\omega=0)$. $\mathbf{F}^{e}$ includes the influence of gravitational forces.

The disk is modelled as a rigid disk and may be written as

$$
\left(\mathbf{M}_{T}^{d}+\mathbf{M}_{R}^{d}\right) \ddot{\mathbf{X}}^{d}-\omega \mathbf{G}^{d} \dot{\mathbf{X}}^{d}=\mathbf{F}^{d}
$$

where $\mathbf{M}_{T}^{d}, \mathbf{M}_{R}^{d}$ and $\mathbf{G}^{d}$ are respectively the translational mass, the rotary mass and the gyroscopic matrices. $\mathbf{F}^{d}$ defines the imbalance and gravitational forces.

Finally, discrete bearing stiffness components are located at either end of the shaft, after assembling the various shaft elements and the rigid disc. The equations of the uncracked rotor can be written as

$$
\mathbf{M} \ddot{\mathbf{X}}+\mathbf{D} \ddot{\mathbf{X}}+\mathbf{K X}=\mathbf{g}(t)
$$

where $\mathbf{g}(t)$ contains the balance and gravitational forces. The mass matrix $\mathbf{M}$ includes the mass matrices of the shaft and the rigid disc. The matrix $\mathbf{D}$ combines the effects of the shaft's internal damping, damping of the supports, and gyroscopic moments. The matrix $\mathbf{K}$ includes the stiffness matrices of the shaft and the supports, together with the circulatory matrix which accounts for the shaft's internal damping.

\subsection{Crack modelling}

Firstly, the presence of a transverse crack introduces local flexibility, due to strain energy concentration in the vicinity of the tip of the crack under load. In order to provide cross section representation of the stiffness properties of the crack, Mayes and Davies [24,25] proposed a theoretical model of a transverse crack, by reducing the second moment of area of the element at the location of the crack by $\Delta I$, and by using Green's functions for the shaft section with the crack. They obtained the expression

$$
\Delta I=I_{0}\left(\frac{\frac{R}{l}\left(1-\nu^{2}\right) F(\mu)}{1+\frac{R}{l}\left(1-\nu^{2}\right) F(\mu)}\right)
$$

where $I_{0}, R, l$, and $\nu$ are the second moments of area, shaft radius, length of the section and Poisson's ratio, respectively. $\mu$ is the non-dimensional crack depth and is given by

$$
\mu=\frac{h}{R}
$$


where $h$ defines the crack depth of the shaft, as shown in Figure 1. $F(\mu)$ defines the non-linear compliance as a function of variations in non-dimensional crack depth $\mu$, which can be derived from a series of experiments using chordal cracks (see Mayes and Davies [24,25]). At the transverse crack location, the stiffness matrix $\mathbf{K}_{\text {crack }}$ is defined (with respect to the principal axes of the crack front) as

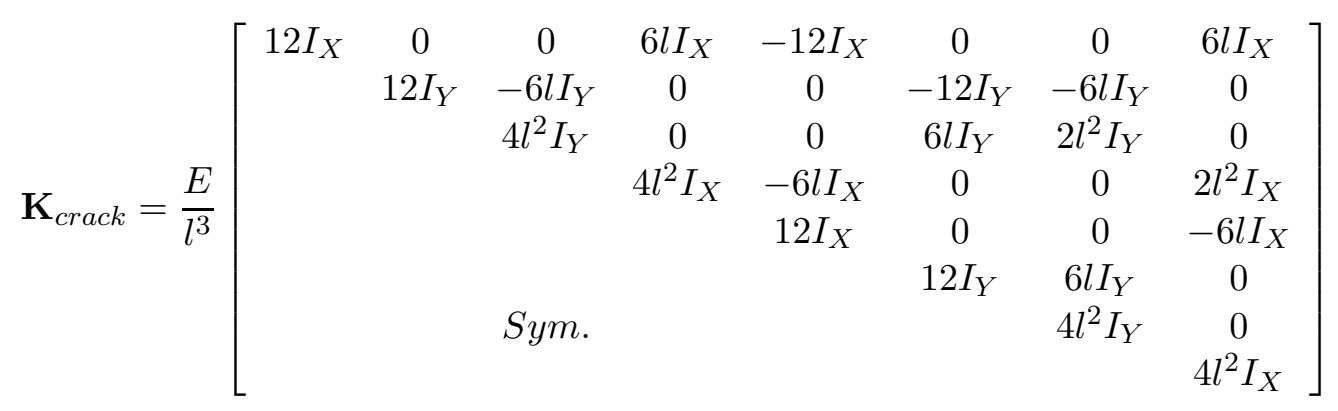

where $I_{X}$ and $I_{Y}$ are the new moments of inertia, about the parallel centroidal axes, due to the presence of the cracked elements. They are given by [14]

$$
\begin{gathered}
I_{X}=\tilde{I}_{X} \\
I_{Y}=\tilde{I}_{Y}-A \bar{X}^{2}
\end{gathered}
$$

where $\bar{X}^{2}$ and $A$ define the uncracked area of the cross-section and the distance from the axis $X$ to the centroid of the cross section

$$
\begin{gathered}
\bar{X}=\frac{2}{3 A} R^{3} \gamma^{3} \\
A=R^{2}\left((1-\mu) \gamma+\frac{\alpha}{2}\right)
\end{gathered}
$$

where $\gamma$ is equal to $\sqrt{2 \mu-\mu^{2}}$ for convenience.

As illustrated in Figure 1, $\alpha$ defines the crack angle and is given by

$$
\alpha=2 \cos ^{-1}(1-\mu)
$$

Then, the asymmetric area moments of inertia $\tilde{I}_{X}$ and $\tilde{I}_{Y}$ about the $\mathrm{X}$ and Y-axes are defined by:

$$
\begin{gathered}
\tilde{I}_{X}=\iint_{A} Y^{2} d A=\frac{R^{4}}{4}\left((1-\mu)\left(1-4 \mu+2 \mu^{2}\right) \gamma+\frac{\alpha}{2}\right) \\
\tilde{I}_{Y}=\iint_{A} X^{2} d A=\frac{\pi R^{4}}{4}+R^{4}\left(\frac{2}{3}(1-\mu) \gamma^{3}+\frac{1}{4}(1-\mu)\left(1-4 \mu+2 \mu^{2}\right) \gamma+\sin ^{-1}(\gamma)\right)
\end{gathered}
$$

In order to model the simple crack breathing phenomenon, it is commonly assumed that gravity determines the breathing of the crack, due to weight dominance. This reflects the fact that the static deflection of a cracked rotor is much greater than its dynamic response during rotation. The opening and closing of the crack may be approximated by a cosine function $f(t)$

$$
f(t)=\frac{1-\cos \omega t}{2}
$$

where $\omega$ defines the rotational speed of the rotor. If $f(t)=0$, the crack is closed and has no effect on the dynamic behaviour of the rotor. If $f(t)=1$, the crack is fully open. 


\subsection{Equations of motion of the cracked rotor}

Finally, the equations of the cracked rotor can be written as

$$
\mathbf{M} \ddot{\mathbf{X}}+\mathbf{D} \dot{\mathbf{X}}+\left(\mathbf{K}-\mathbf{K}_{c}(t)\right) \mathbf{X}=\mathbf{g}(t)
$$

where $\mathbf{M}$ and $\mathbf{K}$ are the mass and stiffness matrices of the complete uncracked rotor. $\mathbf{g}(t)$ contains the balance and gravitational forces. It may be noted that the global stiffness matrix of the rotor consists of a constant component $\mathbf{K}$ and a time dependent component $\mathbf{K}_{c}=f(t) \mathbf{K}_{\text {crack }}$.

As previoulsy indicated, the crack can open and close due to the self-weight bending and out-of-balance forces acting on the rotating shaft. This phenomenon means that the Equations 15 of the cracked rotor are non-linear. Therefore, in order to obtain the non-linear responses of the cracked rotor system, the Harmonic Balance Method will be used.
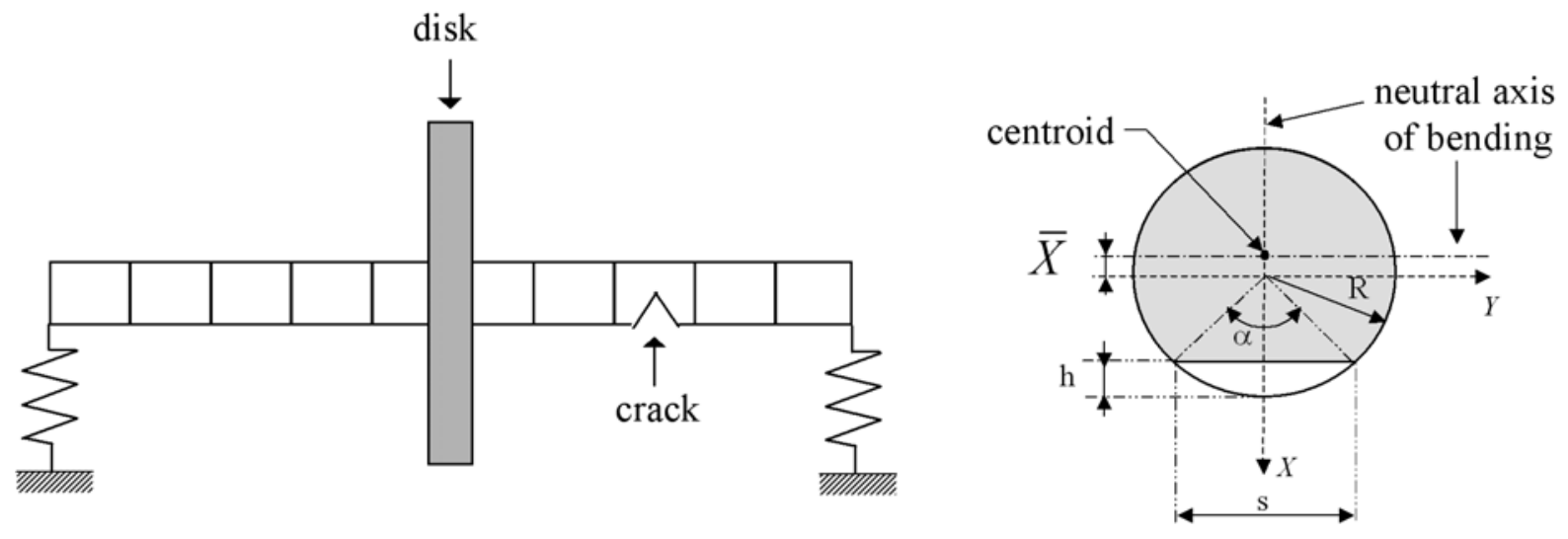

Figure 1: Finite-element model of the rotor and the cracked-beam section.

\begin{tabular}{ccc}
\hline Notation & Description & Value \\
\hline$R$ & radious of the rotor shaft & $0.005 \mathrm{~m}$ \\
$L$ & length of the rotor shaft & $0.5 \mathrm{~m}$ \\
$R_{D}$ & outer radius of the disk & $0.025 \mathrm{~m}$ \\
$h_{D}$ & thickness of the disk & $0.015 \mathrm{~m}$ \\
$E$ & Young's modulus of elasticity & $2.110^{11} \mathrm{~N} . \mathrm{m}^{-2}$ \\
$G$ & shear modulus & $7.710^{10} \mathrm{~N} . \mathrm{m}^{-2}$ \\
$\rho$ & density & $7800 \mathrm{~kg} . \mathrm{m}^{-3}$ \\
$\nu$ & Poisson ratio & 0.3 \\
$\eta$ & coefficient of damping & $110^{-6}$ \\
$m$ & mass unbalance & $1 \mathrm{~g}$ \\
$e$ & eccentricity of the mass unbalance & $0.01 \mathrm{~m}^{-1}$ \\
$K_{s}$ & stiffness of supports & $210^{6} \mathrm{~N} . \mathrm{m}^{-1}$ \\
$\omega_{1}$ & first critical speed of the uncracked rotor & $317 \mathrm{rad} . \mathrm{s}^{-1}$ \\
$\omega_{3}$ & second critical speed of the uncracked rotor & $1898 \mathrm{rad} . \mathrm{s}^{-1}$ \\
$\omega_{5}$ & third critical speed of the uncracked rotor & $3332 \mathrm{rad} . \mathrm{s}^{-1}$ \\
\hline
\end{tabular}

Table 1: Value of the physical parameters 


\section{Non-linear analysis}

Due to the complexity of non-linear systems, and the considerable time and effort needed to solve them, many methods have been developed in order to simplify and reduce non-linear equations. The reader may wish to refer to [26-28] for a survey of some recent developments and alternative approaches.

One of the most popular techniques used to approximate the non-linear responses of a system is the harmonic balance method in which the non-linear solution is assumed to be a truncated Fourier series. With this method, stability analysis can be applied to the derived periodic solutions, by making use of small perturbations.

The present section provides an overview of the Harmonic Balance Method and associated stability analysis, which have been essential to the determination of results presented in this paper. We refer the interested reader to [14] for an extensive overview of this non-linear method.

\subsection{Harmonic balance method}

In order to determine the periodic solutions of the non-linear cracked rotor system, the previous nonlinear equations of motion of the cracked rotor may be rewritten as

$$
\mathbf{M} \ddot{\mathbf{X}}+\mathbf{D} \dot{\mathbf{X}}+\mathbf{K X}=\mathbf{f}_{N L}(\mathbf{X}, \omega, t)
$$

with

$$
\mathbf{f}_{N L}(\mathbf{X}, \omega, t)=\frac{1}{2}(1-\cos \omega t) \mathbf{K}_{\text {crack }} \cdot \mathbf{X}+\mathbf{g}(t)
$$

The non-linear dynamic response of the rotor can also be approximated by a finite Fourier series with a fundamental frequency $\omega$ :

$$
\mathbf{X}(t)=\mathbf{B}_{0}+\sum_{k=1}^{m}\left(\mathbf{B}_{k} \cos (k \omega t)+\mathbf{A}_{k} \sin (k \omega t)\right)
$$

where $m$ represents the number of harmonics considered in the solution. $\mathbf{B}_{0}, \mathbf{A}_{k}$ and $\mathbf{B}_{k}$ (with $k=$ $1, \cdots, m)$ define the unknown coefficients of the finite Fourier series. The number of harmonic coefficients is selected on the basis of the number of significant harmonics expected in the non-linear dynamic response.

Moreover, it is assumed that the non-linear force $\mathbf{f}_{N L}$ can be approximated by a finite Fourier series of order $m$

$$
\mathbf{f}_{N L}(\mathbf{X}, \omega, t)=\mathbf{C}_{0}+\sum_{k=1}^{m}\left(\mathbf{C}_{k} \cos (k \omega t)+\mathbf{S}_{k} \sin (k \omega t)\right)
$$

Substituting Equations 18 and 19 into Equation 16, and balancing the harmonic terms yields a set of $(2 m+1) * n$ equations (where $n$ is the number of degrees of freedom for the complete cracked rotor)

$$
\left[\begin{array}{cccccc}
\mathbf{K} & & & & & \\
& \boldsymbol{\Lambda}_{1} & & & & \\
& & \ddots & & & \\
& & & \boldsymbol{\Lambda}_{k} & & \\
& & & & \ddots & \\
& & & & & \boldsymbol{\Lambda}_{m}
\end{array}\right]\left[\begin{array}{c}
\mathbf{B}_{0} \\
\boldsymbol{\Gamma}_{1} \\
\vdots \\
\boldsymbol{\Gamma}_{k} \\
\vdots \\
\boldsymbol{\Gamma}_{m}
\end{array}\right]-\left[\begin{array}{c}
\mathbf{C}_{0} \\
\boldsymbol{\Theta}_{1} \\
\vdots \\
\boldsymbol{\Theta}_{k} \\
\vdots \\
\boldsymbol{\Theta}_{m}
\end{array}\right]=\left[\begin{array}{c}
\mathbf{0} \\
\mathbf{0} \\
\vdots \\
\mathbf{0} \\
\vdots \\
\mathbf{0}
\end{array}\right]
$$

where

$$
\boldsymbol{\Lambda}_{k}=\left[\begin{array}{cc}
\mathbf{K}-k^{2} \omega^{2} \mathbf{M} & -k \omega \mathbf{D} \\
k \omega \mathbf{D} & \mathbf{K}-k^{2} \omega^{2} \mathbf{M}
\end{array}\right]
$$




$$
\begin{aligned}
& \boldsymbol{\Gamma}_{k}=\left[\begin{array}{l}
\mathbf{A}_{k} \\
\mathbf{B}_{k}
\end{array}\right] \\
& \boldsymbol{\Theta}_{k}=\left[\begin{array}{l}
\mathbf{S}_{k} \\
\mathbf{C}_{k}
\end{array}\right]
\end{aligned}
$$

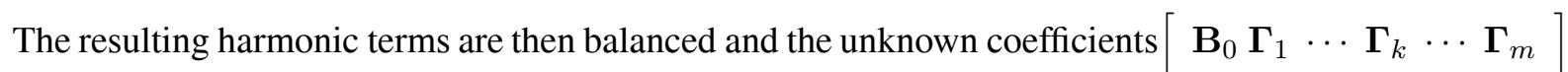
can be found. The roots of Equation 20 may be found by using a Newton-Raphson algorithm or the Broyden method.

To establish the relation between the forcing and the displacement coefficients (i.e. $\mathbf{B}_{0}$ and $\boldsymbol{\Gamma}_{k}$, and $\mathbf{C}_{0}$ and $\boldsymbol{\Theta}_{k}$, respectively) the Alternate Frequency-Time strategy is employed: Cameron and Griffin [29] suggested that the truncated Fourier expression $\mathbf{f}_{N L}$ could be calculated by applying an iterative process, which is outlined by the following:

$$
\left[\begin{array}{l}
\mathbf{B}_{0} \boldsymbol{\Gamma}_{1} \cdots \boldsymbol{\Gamma}_{k} \cdots \boldsymbol{\Gamma}_{m}
\end{array}\right]^{T} \Rightarrow \mathbf{X}(t) \Rightarrow \mathbf{f}_{N L}(\mathbf{X}, \omega, t) \Rightarrow\left[\begin{array}{llllll}
\mathbf{C}_{0} & \boldsymbol{\Theta}_{1} & \cdots & \boldsymbol{\Theta}_{k} & \cdots & \boldsymbol{\Theta}_{m}
\end{array}\right]^{T}
$$

Firstly, an estimation of the Fourier coefficients $\left(\mathbf{B}_{0}\right.$ and $\left.\boldsymbol{\Gamma}_{k}\right)$ is used to synthesize the displacement $\mathbf{X}(t)$. The latter vector is then used to evaluate the nonlinear forces $\mathbf{f}_{N L}(\mathbf{X}, \omega, t)$ in the time domain. Finally, Fourier analysis of these forces gives the coefficients $\mathbf{C}_{0}$ and $\boldsymbol{\Theta}_{k}$.

Moreover, due to the fact that the non-linear behaviour is estimated over a range of rotational speeds for the cracked rotor, a path-following continuation [30] is applied in conjunction with the harmonic balance method, in order to estimate the non-linear response of the cracked rotor system when the rotational speed increases. The estimated point on the solution branch is predicted at a chosen arc length by applying the Lagrangian polynomial extrapolation method. Any point on the solution branch is represented at $\left(\mathbf{X}, \omega_{i}\right)$ where $\mathbf{X}_{i}$ and $\omega_{i}$ define the Fourier coefficients and the rotational speed of the cracked rotor. Then, the arc length between two consecutive points $\left(\mathbf{X}_{i}, \omega_{i}\right)$ and $\left(\mathbf{X}_{i+1}, \omega_{i+1}\right)$ is given by

$$
\Delta S_{i+1}=\sqrt{\left(\left(\mathbf{X}_{i+1}-\mathbf{X}_{i}\right)^{T}\left(\mathbf{X}_{i+1}-\mathbf{X}_{i}\right)+\left(\omega_{i+1}-\omega_{i}\right)^{2}\right)} \quad i=0, \ldots, 2
$$

The estimation of the following point at distance $\Delta S$ may be predicted by using the Lagrangian extrapolation scheme

$$
\left[\begin{array}{c}
\mathbf{X}_{4} \\
\omega_{4}
\end{array}\right]=\sum_{i=1}^{3} \prod_{j=0, i \neq j}^{3}\left(\frac{S_{3}-S_{j}}{S_{i}-S_{j}}\right)\left[\begin{array}{c}
\mathbf{X}_{i} \\
\omega_{i}
\end{array}\right] \quad i=0, \ldots, 3
$$

with the arc length parameters given by $\Delta S_{0}=0, S_{1}=\Delta S_{1}, S_{2}=S_{1}+\Delta S_{2}, S_{3}=S_{2}+\Delta S_{3}$ and $\Delta S_{4}=S_{3}+\Delta S$.

\subsection{Stability analysis}

Even if the non-linear solution for the cracked rotor can be calculated by the harmonic balance method, the stability of this solution is not predicted by the algorithm. Stability in the time-domain is usually determined by the well-known Floquet multipliers and by determining the monodromy matrix [30]. This procedure is however both time consuming and costly to implement. In order to conserve the inherent advantages of the frequential method (low computational costs and greater speed when compared with direct integration), frequential stability analysis can be performed at the end of the previous iteration procedure [31]. It should be recalled that the results given by stability analysis of a non-linear cracked system are directly related to the number of harmonics used. A sufficient number of the latter must be 
therefore be used, to prevent the analysis from artificially degrading the diagnosis.

The proposed approach is based on the effect of a perturbation $\mathbf{Y}$ around the periodic solution $\mathbf{X}^{*}$ :

$$
\mathbf{X}=\mathbf{X}^{*}+\mathbf{Y} e^{\lambda t}
$$

By substituting this relation into Equation 16, one has

$\mathbf{M} \ddot{\mathbf{X}}^{*}+\mathbf{D} \dot{\mathbf{X}}^{*}+\mathbf{K} \mathbf{X}^{*}+e^{\lambda t}\left(\lambda^{2} \mathbf{M Y}+\lambda(2 \mathbf{M} \dot{\mathbf{Y}}+\mathbf{D Y})+\mathbf{M} \ddot{\mathbf{Y}}+\mathbf{D} \dot{\mathbf{Y}}+\mathbf{K Y}\right)=\mathbf{f}_{N L}\left(\mathbf{X}^{*}+e^{\lambda t} \mathbf{Y}\right)$

Applying the harmonic balance procedure to the resulting equation of motion, one obtains

$$
\boldsymbol{\Lambda} \mathbf{Z}^{*}+\left(\boldsymbol{\Lambda}+\lambda \boldsymbol{\Xi}_{1}+\lambda^{2} \boldsymbol{\Xi}_{2}\right) \overline{\mathbf{Z}} e^{\lambda t}=\mathbf{b}_{N L}\left(\mathbf{Z}^{*}+e^{\lambda t} \overline{\mathbf{Z}}\right)
$$

where $\mathbf{Z}^{*}$ and $\overline{\mathbf{Z}}$ are the vectors containing the Fourier coefficients of $\mathbf{X}^{*}$ and $\mathbf{Y}$, respectively. $\mathbf{b}_{N L}$ defines the vector containing the Fourier coefficients of $\mathbf{f}_{N L}$.

The matrices $\boldsymbol{\Lambda}, \boldsymbol{\Xi}_{1}$ and $\boldsymbol{\Xi}_{2}$ are given by

$$
\begin{aligned}
& \boldsymbol{\Lambda}=\left[\begin{array}{llllll}
\mathbf{K} & & & & & \\
& \boldsymbol{\Lambda}_{1} & & & & \\
& & \ddots & & & \\
& & & \boldsymbol{\Lambda}_{k} & & \\
& & & & \ddots & \\
& & & & & \boldsymbol{\Lambda}_{m}
\end{array}\right] \\
& \boldsymbol{\Xi}_{1}=\left[\begin{array}{llllll}
\mathbf{D} & & & & & \\
& \tilde{\boldsymbol{\Delta}}_{1} & & & & \\
& & \ddots & & & \\
& & & \tilde{\boldsymbol{\Delta}}_{k} & & \\
& & & & \ddots & \\
& & & & & \tilde{\boldsymbol{\Delta}}_{m}
\end{array}\right] \\
& \boldsymbol{\Xi}_{2}=\left[\begin{array}{llllll}
\mathbf{M} & & & & & \\
& \mathbf{M} & & & & \\
& & \ddots & & & \\
& & & \mathbf{M} & & \\
& & & & \ddots & \\
& & & & & \mathbf{M}
\end{array}\right]
\end{aligned}
$$

with

$$
\begin{gathered}
\boldsymbol{\Lambda}_{k}=\left[\begin{array}{cc}
\mathbf{K}-k^{2} \Omega^{2} \mathbf{M} & -k \Omega \mathbf{D} \\
k \Omega \mathbf{D} & \mathbf{K}-k^{2} \Omega^{2} \mathbf{M}
\end{array}\right] \\
\tilde{\boldsymbol{\Delta}}_{k}=\left[\begin{array}{cc}
\mathbf{D} & -2 k \Omega \mathbf{M} \\
2 k \Omega \mathbf{M} & \mathbf{D}
\end{array}\right]
\end{gathered}
$$

The linearization of $\mathbf{b}_{N L}(\mathbf{X})$ with respect to $e^{\lambda t} \overline{\mathbf{Z}}$ gives:

$$
\mathbf{b}_{N L}\left(\mathbf{Z}^{*}+e^{\lambda t} \overline{\mathbf{Z}}\right) \approx \mathbf{b}_{N L}\left(\mathbf{Z}^{*}\right)+\mathbf{J}_{\mathbf{b}_{N L}}\left(\mathbf{Z}^{*}\right) \cdot e^{\lambda t} \overline{\mathbf{Z}}
$$


where $\mathbf{J}_{\mathbf{b}_{N L}}$ is the Jacobian matrix of the function $\mathbf{b}_{N L}$. Considering Equations 29-35, one obtains the eigenvalue problem

$$
\left(\lambda \boldsymbol{\Xi}_{1}+\lambda^{2} \boldsymbol{\Xi}_{2}+\boldsymbol{\Lambda}-\mathbf{J}_{\mathbf{b}_{N L}}\left(\mathbf{Z}^{*}\right)\right) \overline{\mathbf{Z}}=\mathbf{0}
$$

Finally, the determination of the eigenvalues of Equation 36 provide us with information related to the stability of the cracked rotor. The solution for the cracked rotor is stable if the real part of all eigenvalues is negative, since the perturbation $\mathbf{Y} e^{\lambda t}$ of Equation 27 decays with time. If at least one of the eigenvalues has a positive real part, the solution is unstable.

\section{Results and discussions}

\subsection{Unbalanced response of the cracked rotor}

Before discussing the stability of the non-linear periodic solutions for the cracked rotor system, and investigating the effects of the crack and other system parameters on its dynamic stability, a brief summary is given of the main dynamic characteristics of a cracked rotor system.

Figures 2 and 3 show the vertical and horizontal steady-state responses of the cracked and uncracked rotor at a position $0.15 \mathrm{~m}$ along the shaft, for two different positions of the imbalance location. Figures 4(a) and (b) show the vertical steady-state responses of the cracked shaft for each of its nodes.

Firstly, it may be observed that the horizontal and vertical responses of the cracked rotor reveal a decrease in the critical speeds of the rotor system (see marks 3,6,7,9,11 and 12) due to the reduction in system stiffness induced by the presence of the crack. Table 2 shows how the pulsations $\omega_{\imath}^{\text {cracked }}$ of the cracked rotor system vary as a function of the crack's depth and location.

However these variations in critical speed, between the cracked and uncracked rotors, are too small to enable the existence of a crack to be detected in a rotating shaft.

Secondly, it appears that the motion of the cracked rotor is complicated due to the existence of the $2 \times$ and $3 \times$ frequencies of the rotational speed in the vibration signals (see marks 1, 2, 4, 5 and 8 in Figures 2- 4). However, it should be recalled that the period of these motions is equal to the period of the exciting force. For example, the vertical response of the cracked rotor at $\frac{1}{3}$ and $\frac{1}{2}$ of the first critical speed (see marks 1 and 2 in Figures 2-4) generates highly prominent $2 \times$ and $3 \times$ frequency components, which are well known clues for the detection of a tranverse crack in a rotating shaft. For the horizontal response of the cracked rotor at $1 / 2$ of the first critical speed (see mark 8 in Figures 2-3), it appears that the $2 \times$ frequency component is predicted when the running speed is approximately $\frac{1}{2}$ of the first critical speed, although this resonance is quite small when compared to the $2 \times$ and $3 \times$ frequency components observed for vertical displacements. Moreover, vertical response peaks of the cracked rotor are also present at $\frac{1}{2}$ of the second and third critical speeds (see marks 4 and 5 respectively), but are quite small when compared to those observed at $\frac{1}{2}$ of the first critical speed (see mark 2).

As illustrated in Figures 5(b), the orbits at $\frac{1}{2}$ of the first critical speed exhibit the well-known double loop, typical of a cracked shaft rotating close to half its critical speed [15]. Similarly, a triple loop is observed at 1/3 of the first critical speed (see Figure 5(a)). Finally, a distorsion of the orbits is observed at $\frac{1}{2}$ the second critical speed, and the inner loop does not appear, as illustrated in Figure 5(c).

It may thus be concluded that the first measure to be taken, towards the detection of cracks in rotating systems, should be based on the observation of vibrations near to $\frac{1}{2}$ and $\frac{1}{3}$ of the first critical speed of the rotor. It it also recalled that the crack depth and location clearly affect the critical speeds of the cracked rotor and the vibrational amplitudes of the sub-critical resonances $[14,15]$. 

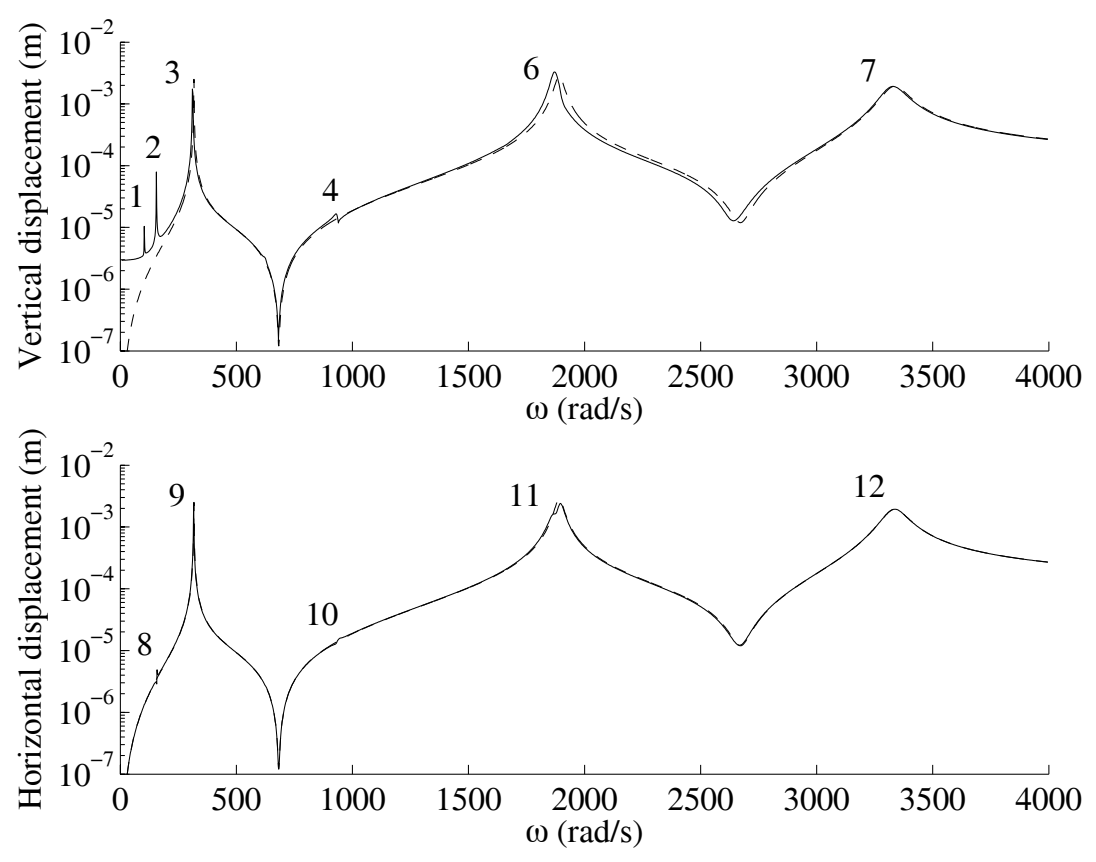

Figure 2: Vertical and horizontal steady-state responses of the cracked and uncracked rotor at $0.15 \mathrm{~m}$ of the left end with the imbalance situated at $0.1 m$ from the left end (-- uncracked, - cracked with $L_{\text {crack }}=0.175 m$ and $\mu=1$ )
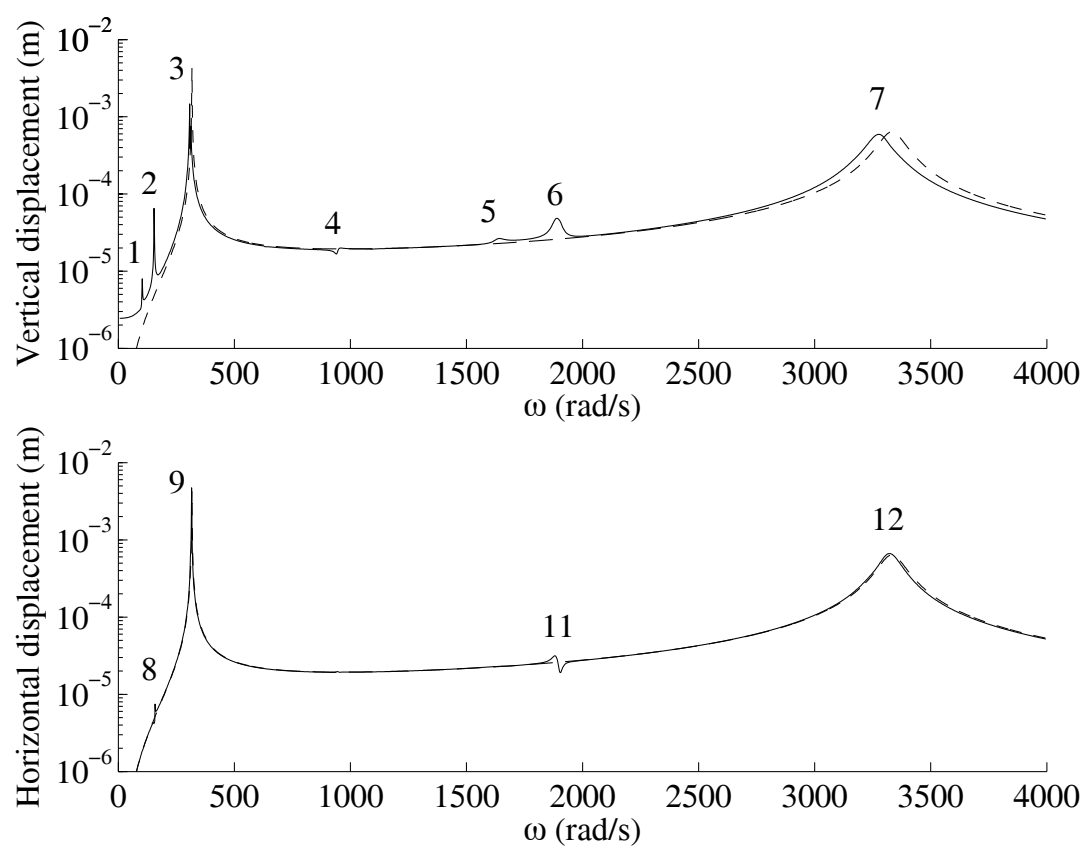

Figure 3: Vertical and horizontal steady-state responses of the cracked and uncracked rotor at $0.15 \mathrm{~m}$ of the left end with the imbalance situated at $0.25 \mathrm{~m}$ from the left end (-- uncracked, - cracked with $L_{\text {crack }}=0.225 m$ and $\mu=1$ ) 


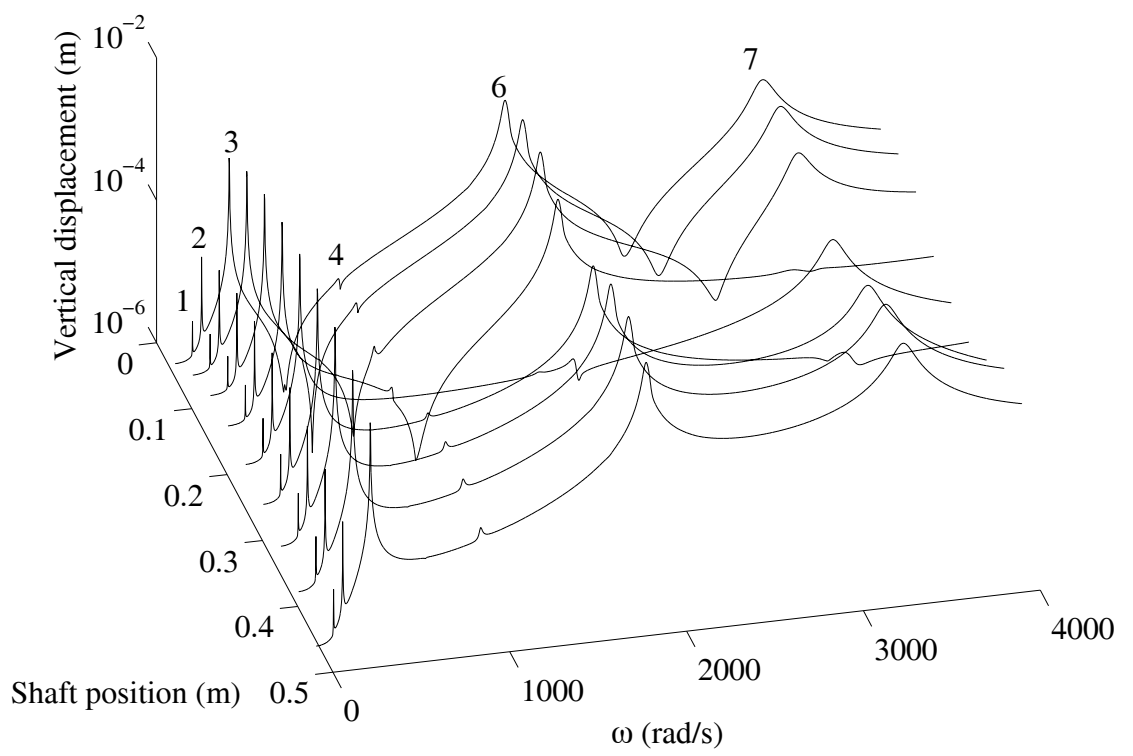

(a) Imbalance at $0.1 \mathrm{~m}, L_{\text {crack }}=0.175 \mathrm{~m}$ and $\mu=1$

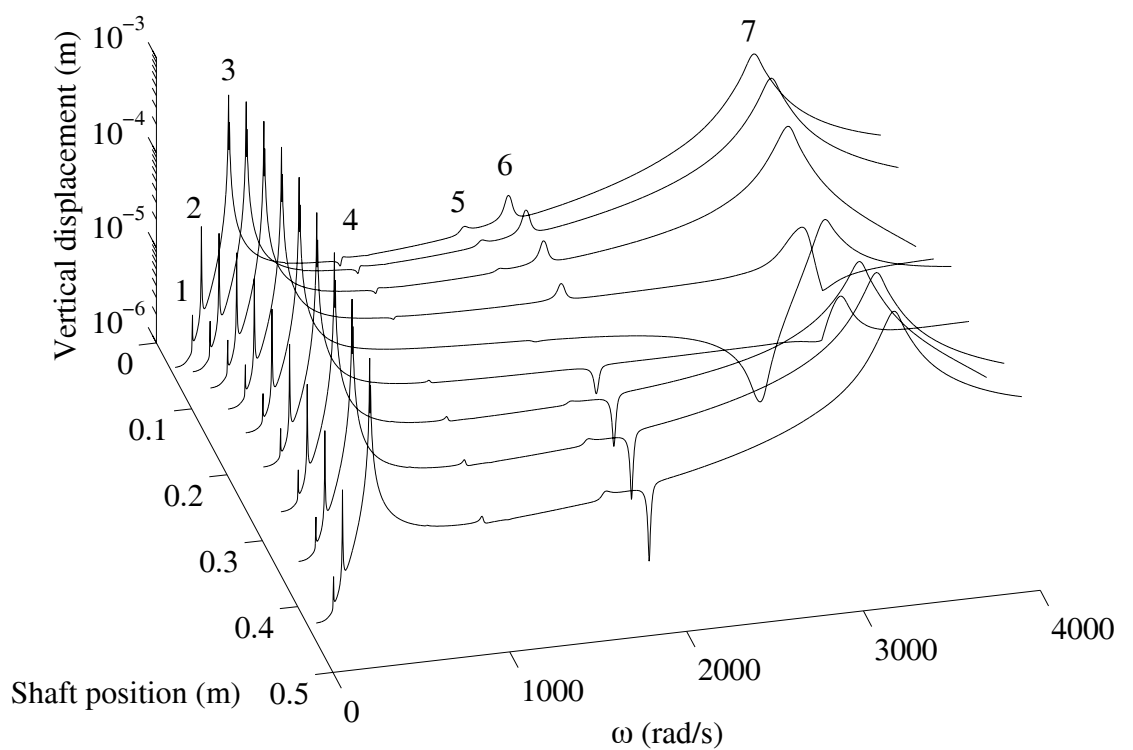

(b) Imbalance at $0.25 \mathrm{~m}, L_{\text {crack }}=0.225 \mathrm{~m}$ and $\mu=1$

Figure 4: Vertical displacements for the cracked shaft for two imbalance locations 


\begin{tabular}{cccccccc}
\hline$\mu$ & $L_{\text {crack }}(m)$ & $\omega_{1}^{\text {cracked }}$ & $\omega_{2}^{\text {cracked }}$ & $\omega_{3}^{\text {cracked }}$ & $\omega_{4}^{\text {cracked }}$ & $\omega_{5}^{\text {cracked }}$ & $\omega_{6}^{\text {cracked }}$ \\
\hline 1 & 0.225 & 299 & 314 & 1884 & 1895 & 3200 & 3308 \\
1 & 0.175 & 305 & 315 & 1839 & 1887 & 3319 & 3330 \\
1 & 0.125 & 310 & 316 & 1811 & 1882 & 3257 & 3318 \\
1 & 0.075 & 314 & 317 & 1836 & 1887 & 3222 & 3312 \\
0.9 & 0.225 & 305 & 314 & 1889 & 1895 & 3245 & 3308 \\
0.8 & 0.225 & 309 & 314 & 1892 & 1895 & 3273 & 3309 \\
0.7 & 0.225 & 312 & 314 & 1893 & 1895 & 3291 & 3310 \\
0.5 & 0.225 & 314 & 315 & 1896 & 1896 & 3312 & 3316 \\
0.25 & 0.225 & 316 & 316 & 1897 & 1897 & 3326 & 3326 \\
\hline
\end{tabular}

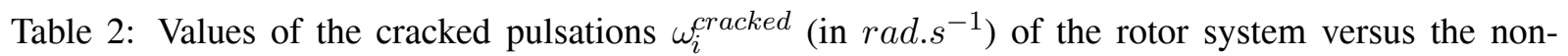
dimensional crack depth $\mu$ and the crack location $L_{\text {crack }}$

\subsection{Stability of the periodic solutions}

Perhaps the most significant and catastrophic effect of the presence of a transverse crack in a rotating shaft is the induced stiffness asymmetry, which can lead to instability in the rotor system. Figure 6 illustrates various regions of dynamic instability. The first plot shows the non-linear response of a cracked rotor system, in which the shaded vertical bars indicate regions of instability. The second plot indicates the maximum real part of the eigenvalues obtained from the eigenproblem described by Equation 36, where a value greater than zero means that the periodic solution of the cracked rotor system is unstable.

The cracked rotor system is thus stable at rotational speeds near to $\frac{1}{2} \times$ and $1 \times$ the first critical speed, even though there is an increase in the maximum real part of the eigenvalues at frequencies near to the first critical speed, as illustrated in Figure 6.

In the following we investigate the influence of crack depth and location, position of the disk and stiffness of the supports, on the main regions of dynamic instability.

\subsubsection{Influence of crack location}

Figures 7, 8 and 9 indicate the main regions of dynamic instability for a cracked rotor system, as a function of crack location (the non-dimensional crack depth $\mu$ is equal to 1 , corresponding to the loss of half of the shaft's area). We recall that the periodic solution for a cracked rotor system is unstable if the maximum real part of the eigenvalues is greater than zero.

When the first main region of dynamic instability is considered (Figure 7), it can be seen that the crack's influence on stability is greater when it is located at mid span, than when it is closer to the antinodal points. Moreover, it can be seen that a small additional region of dynamic instability follows the main region, if the crack is located near to the middle of the shaft, as illustrated in Figure 7 (for $L_{\text {crack }}=0.175 \mathrm{~m}$ and $L_{\text {crack }}=0.225 \mathrm{~m}$ ).

Figure 8 illustrates, for the second main region of dynamic instability (between $2100 \mathrm{rad} / \mathrm{s}$ and $2250 \mathrm{rad} / \mathrm{s}$ ), variations in stability as a function of crack location. As opposed to the behavior observed in the first region of instability, here it can be seen that the smallest zone of dynamic instability occurs when the crack is situated at the middle of the shaft. This is due to the fact that the second main region of dynamic instability can be associated with the vibrational mode which has a node at the middle of the shaft (i.e. the third and fourth pulsations of the cracked rotor).

Figure 9 illustrates the system's behavior in the third main region of dynamic instability (between 


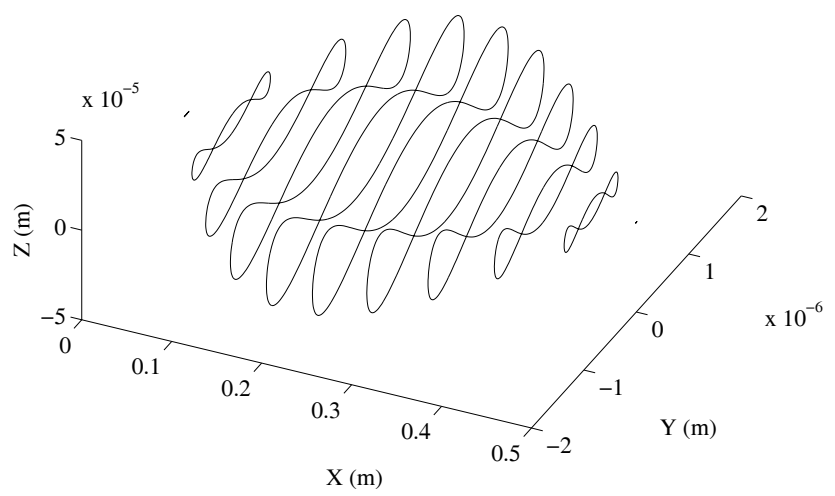

(a) $1 / 3$ of the first critical speed

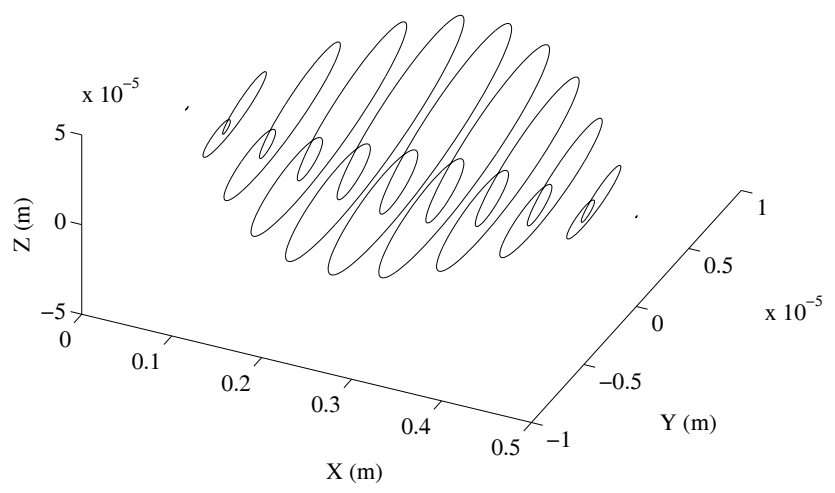

(b) $1 / 2$ of the first critical speed

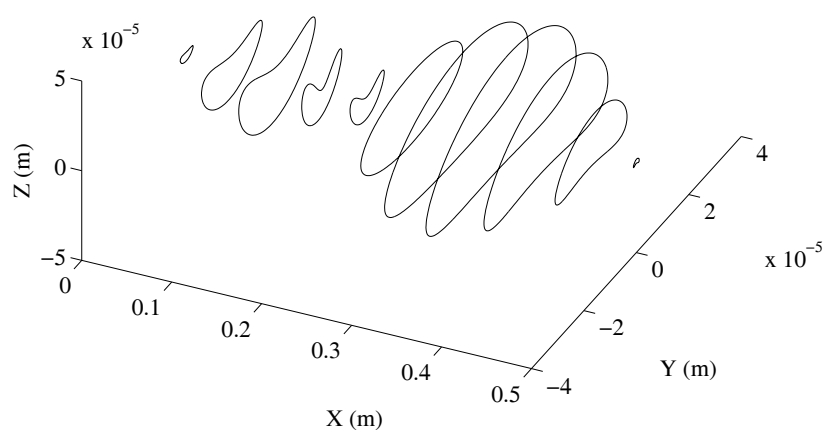

(c) $1 / 2$ of the second critical speed

Figure 5: Evolution of the orbits at various position on the shaft around the static deflection (with $L_{\text {crack }}=0.175 m$ and $\mu=1$ ) 

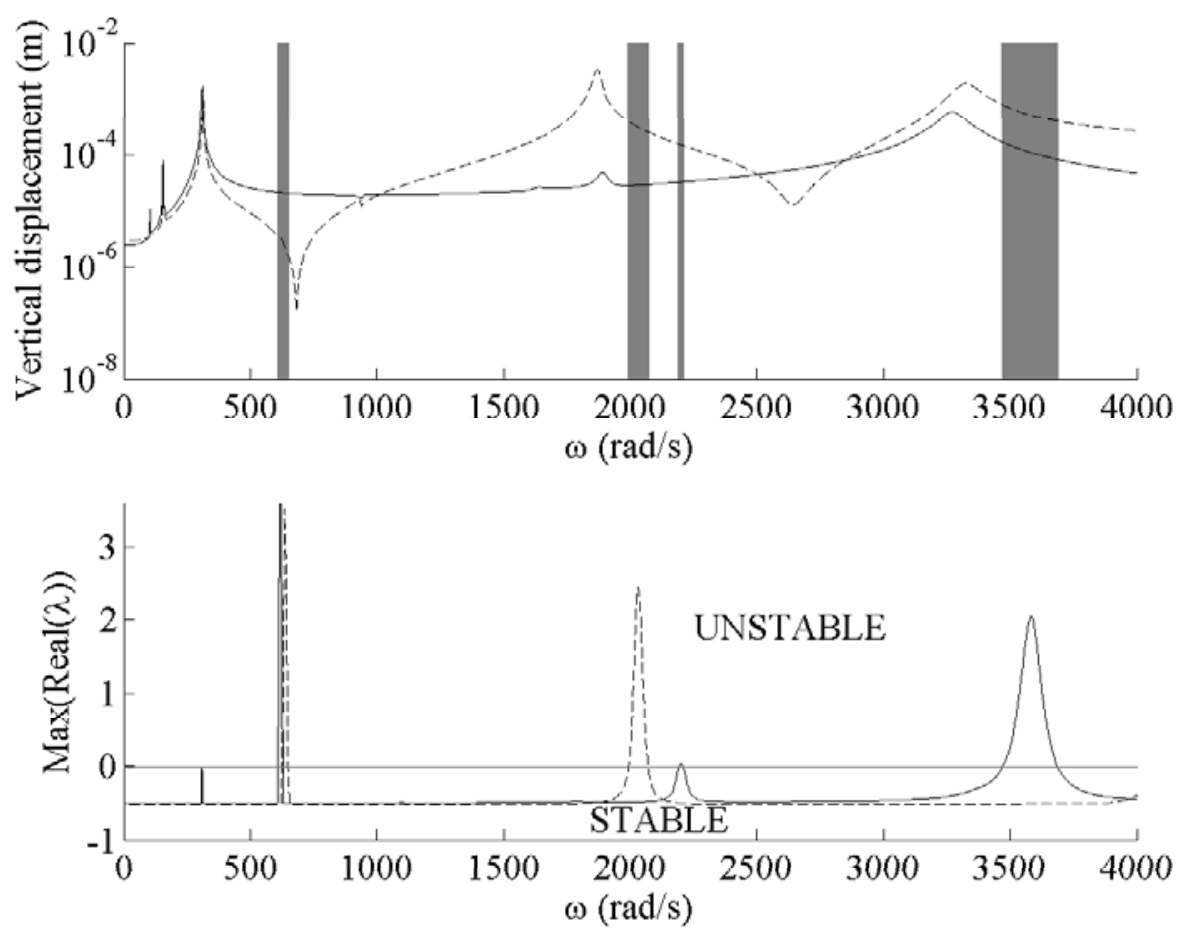

Figure 6: Instability zones on the vertical responses of the cracked rotor at $0.1 \mathrm{~m}$ of the left end and maximum real part of the eigenvalues (-imbalance at $0.25 \mathrm{~m}, L_{\text {crack }}=0.175 \mathrm{~m}$ and $\mu=1$; - imbalance at $0.1 m, L_{\text {crack }}=0.175 m$ and $\mu=1$ ) 
$3400 \mathrm{rad} / \mathrm{s}$ and $3750 \mathrm{rad} / \mathrm{s}$ ), as a function of crack location (when the crack is closer to nodes of the fifth and sixth pulsations of the cracked rotor). It is observed that the smallest region of dynamic instability is obtained when the crack is located at one third of the shaft length. Considering Figures 8 and 9, it can be seen that changes in stability limit are significant when the crack is closer to the antinodal points. An increase in the regions of dynamic instability is accompanied by a decrease in the stability threshold. In conclusion, the influence of a crack's location on the regions of instability is quite similar to that which it has on pulsations: as indicated in Table 2, the pulsations of a cracked rotor system are unchanged when the crack is situated at a node.

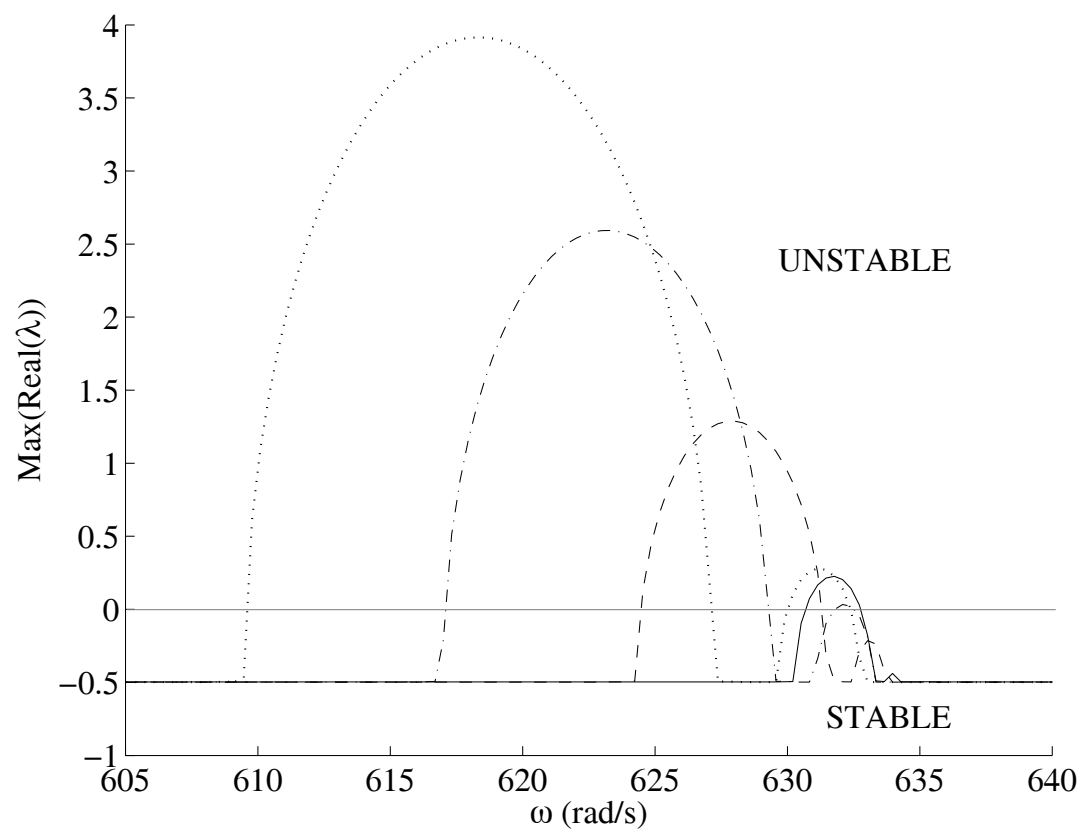

Figure 7: Effects of the crack position on the first region of dynamic instability for the non-dimensional crack depth $\mu=1\left(-L_{\text {crack }}=0.075 m,--L_{\text {crack }}=0.125 m,-.-L_{\text {crack }}=0.175 m, \ldots L_{\text {crack }}=\right.$ $0.225 m$ )

\subsubsection{Effects of crack size}

Figures 10, 11 and 12 illustrate the behavior of the main regions of dynamic instability of a cracked rotor system, as a function of variations in size of the crack. For these three regions, the location of the crack has been chosen in such a way as to highlight the largest zones of instability.

It can be seen that as the crack depth decreases, the regional stability is correspondingly diminished. Moreover, in each case the stability threshold falls quite considerably when the crack depth is increased (see Figures 10, 11 and 12).

If the non-dimensional crack depth $\mu$ is equal to 1 (corresponding to the loss of half of the shaft's cross-section), two regions of dynamic instability arise, at frequencies of approximately $618 \mathrm{rad} / \mathrm{s}$ and $632 \mathrm{rad} / \mathrm{s}$, as shown in Figure 10. The second and third main regions of dynamic instability exist only for deep cracks: they disappear if the non-dimensional crack depth $\mu$ is respectively less than 0.9 or 0.8 , as shown in Figures 11 and 12. 


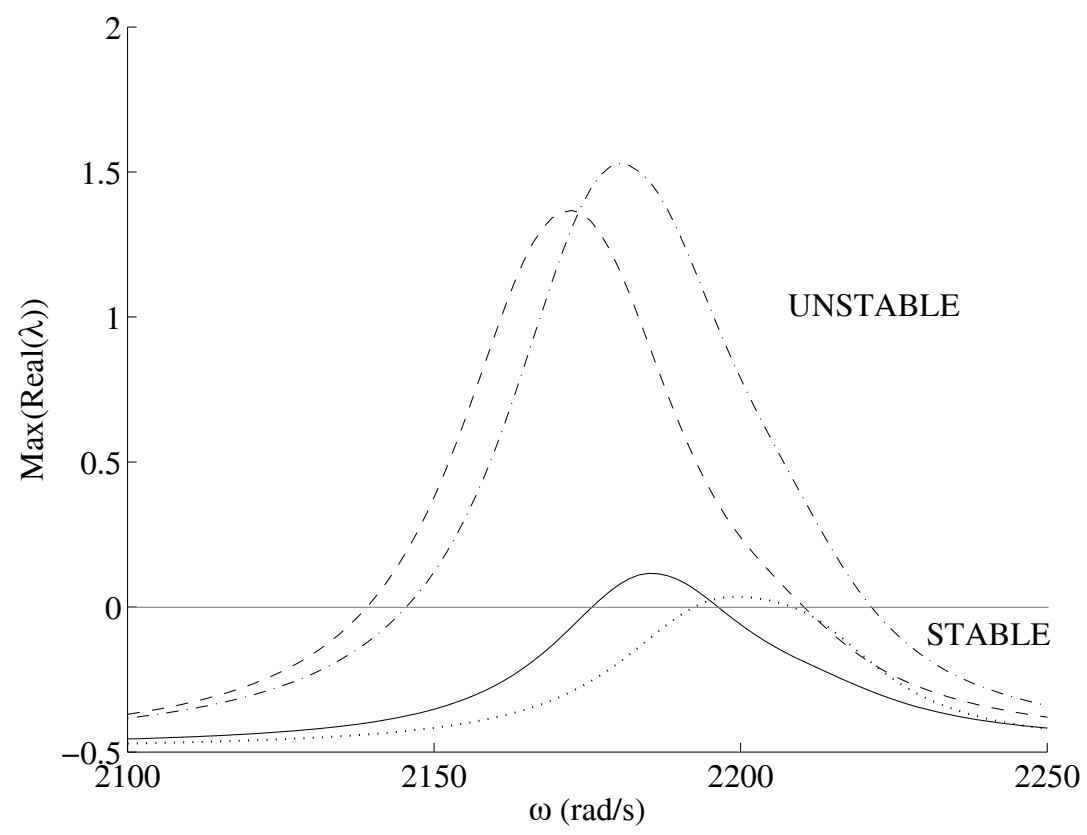

Figure 8: Effects of the crack position on the second region of dynamic instability for the nondimensional crack depth $\mu=1\left(-L_{\text {crack }}=0.075 m,--L_{\text {crack }}=0.125 m,-.-L_{\text {crack }}=0.175 \mathrm{~m}\right.$, $\ldots L_{\text {crack }}=0.225 \mathrm{~m}$ )

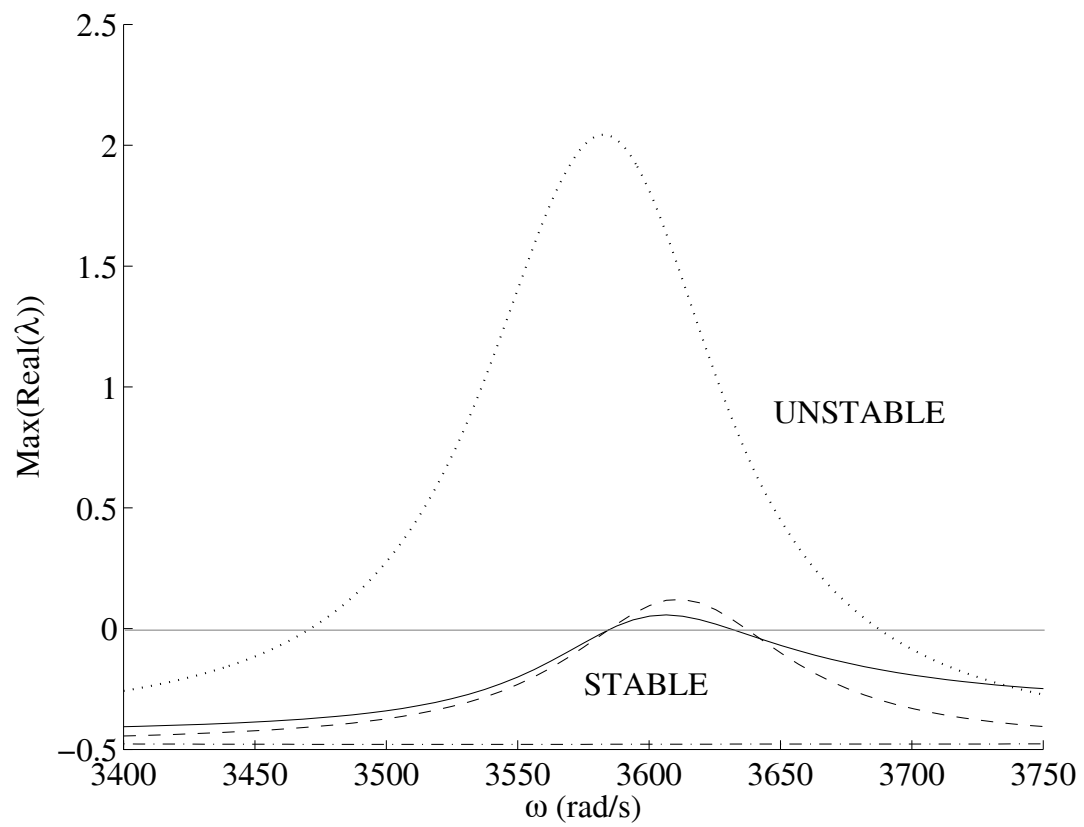

Figure 9: Effects of the crack position on the third region of dynamic instability for the non-dimensional crack depth $\mu=1\left(-L_{\text {crack }}=0.075 m,--L_{\text {crack }}=0.125 m,-.-L_{\text {crack }}=0.175 m, \ldots L_{\text {crack }}=\right.$ $0.225 \mathrm{~m})$ 


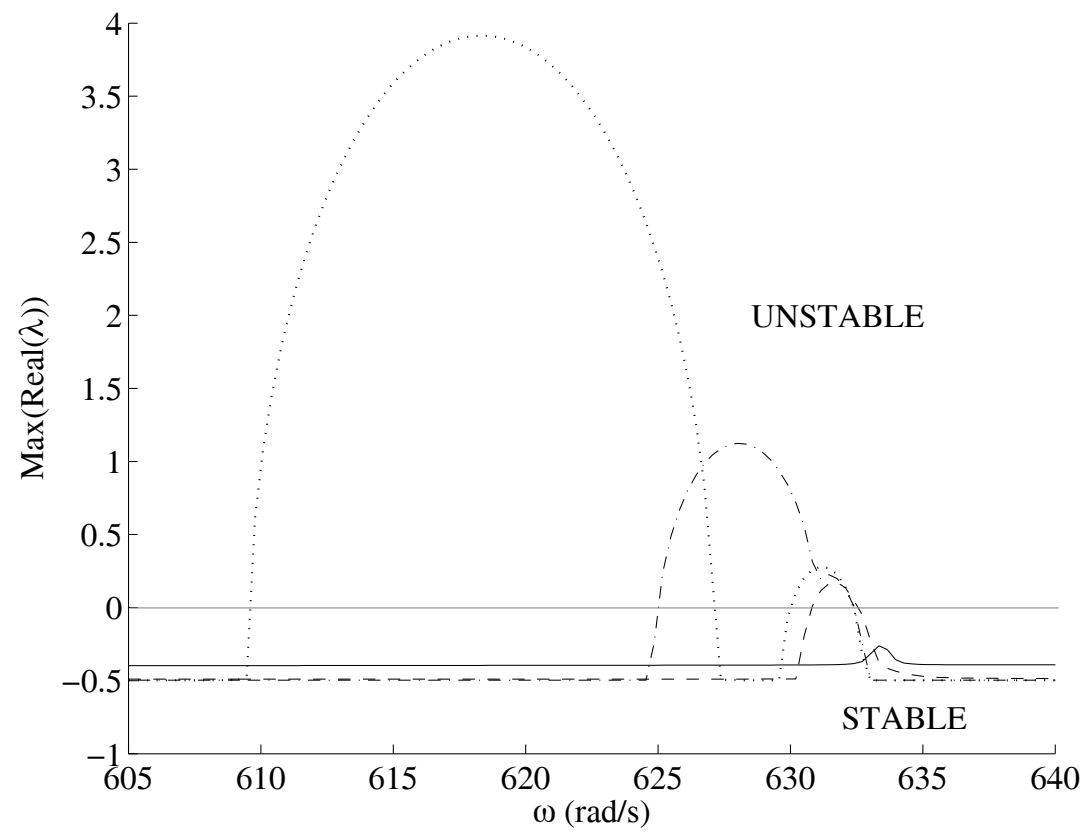

Figure 10: Effects of the crack size on the first region of dynamic instability for the crack location $L_{\text {crack }}=0.225 m(-\mu=0.25,--\mu=0.5,-.-\mu=0.75, \ldots \mu=1)$

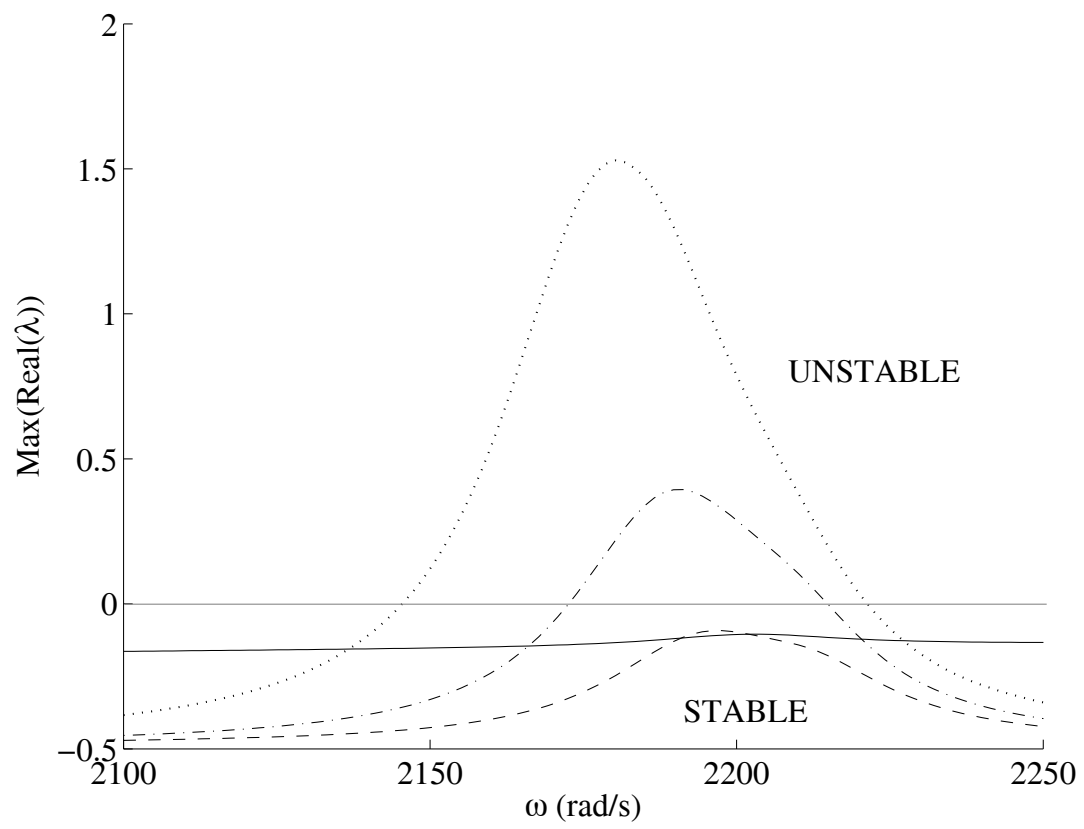

Figure 11: Effects of the crack size on the second region of dynamic instability for the crack location $L_{\text {crack }}=0.175 m(-\mu=0.5,--\mu=0.8,-.-\mu=0.9, \ldots \mu=1)$ 


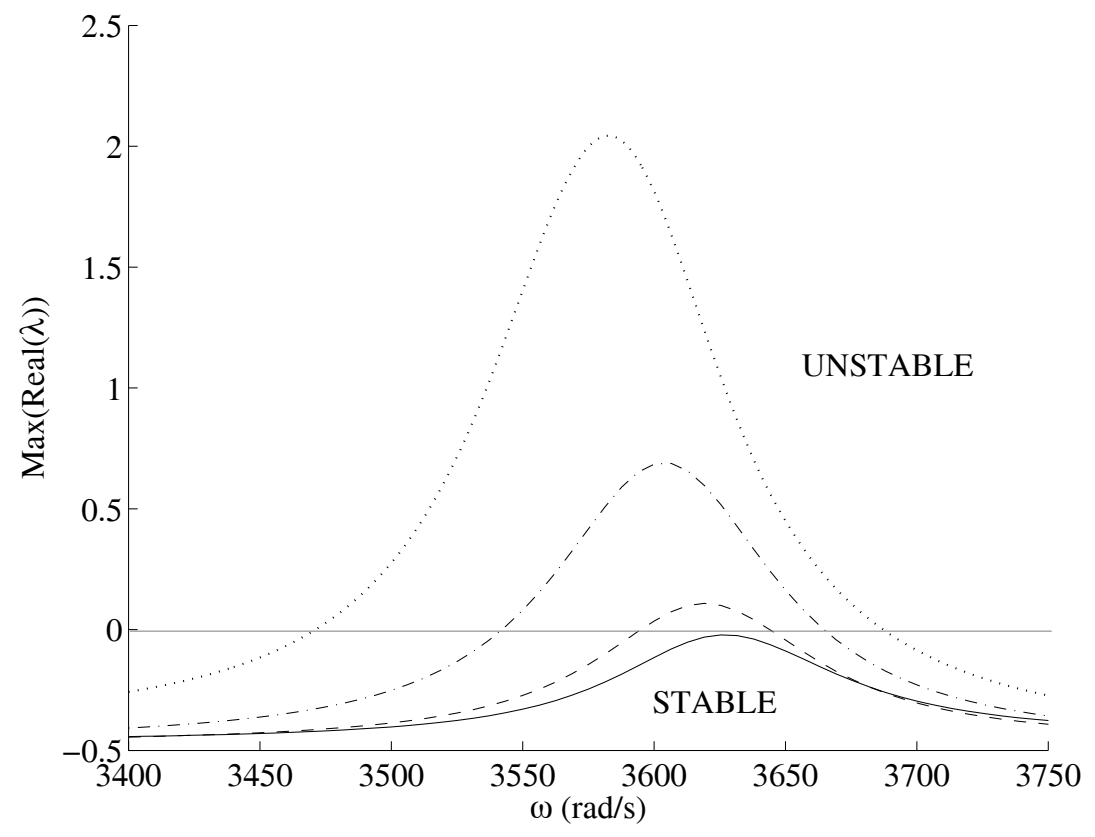

Figure 12: Effects of the crack size on the third region of dynamic instability for the crack location $L_{\text {crack }}=0.225 \mathrm{~m}(-\mu=0.75,--\mu=0.8,-.-\mu=0.9, \ldots \mu=1)$

\subsubsection{Influence of support stiffness}

Figure 13 illustrates the evolution of stability, within the main instability zones, as a function of variations in stiffness of the supports (for two different crack locations and a non-dimensional crack $\mu$ equal to 1). As previously explained, the instability zones decrease when the crack is closer to the nodal points (see Figure 13(a) for the second region of instability, situated between 1600 rad/s and 2400 rad/s, and Figure 13(b) for the third region of instability, situated between $2400 \mathrm{rad} / \mathrm{s}$ and $4000 \mathrm{rad} / \mathrm{s}$ ). By selecting the crack location in such a way as to obtain the largest zones of instability, Figures 14, 15 and 16 illustrate the changes which occur within the main instability regions, as a function of variations in support stiffness. By taking into account the previous results, and the changes in dynamic behaviour of the cracked rotor system as a function of the supports' stiffness, the rotational speed can be normalised with respect to the $(2 i-1)^{t h}$ pulsation of the associated cracked rotor.

The values of the uncracked and cracked rotor systems are given in Table 3 as a function of support stiffness and crack location.

It can be clearly observed that the influence of the supports' stiffness is in general quite considerable: the second and third regions of dynamic instability are strongly reduced if the supports become more flexible, as illustrated in Figures 15 and 16, and the threshold speed limits decrease with increasing support stiffness. It should however be noted that support stiffness does not have a strong influence on stability in the first main region of dynamic instability (see Figure 14): the instability area and threshold speed limits are only slightly decreased when the supports become more flexible. Finally, it is verified that the cracked rotor system still remains stable at rotational speeds in the vicinity of $\frac{1}{2} \times$ and $1 \times$ the first critical speed. 


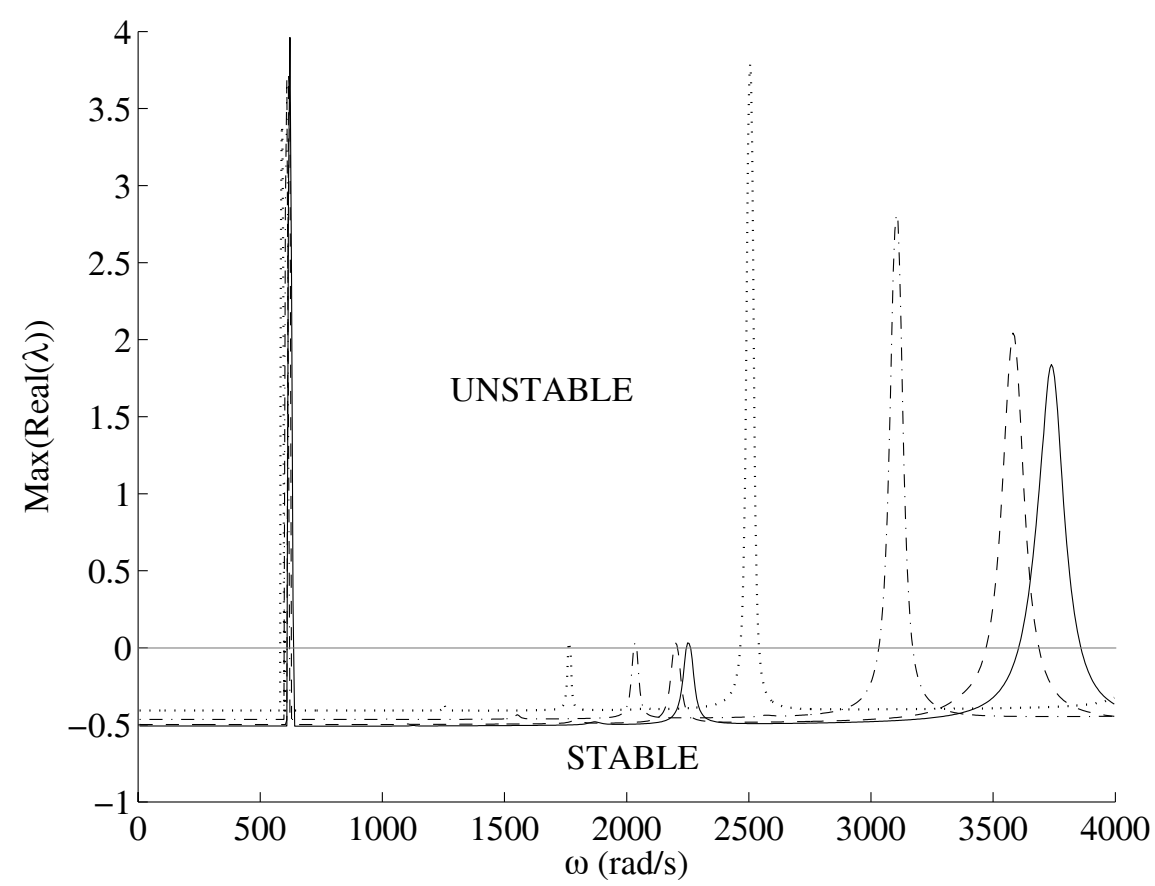

(a) $\mu=1$ and $L_{\text {crack }}=0.225 \mathrm{~m}$

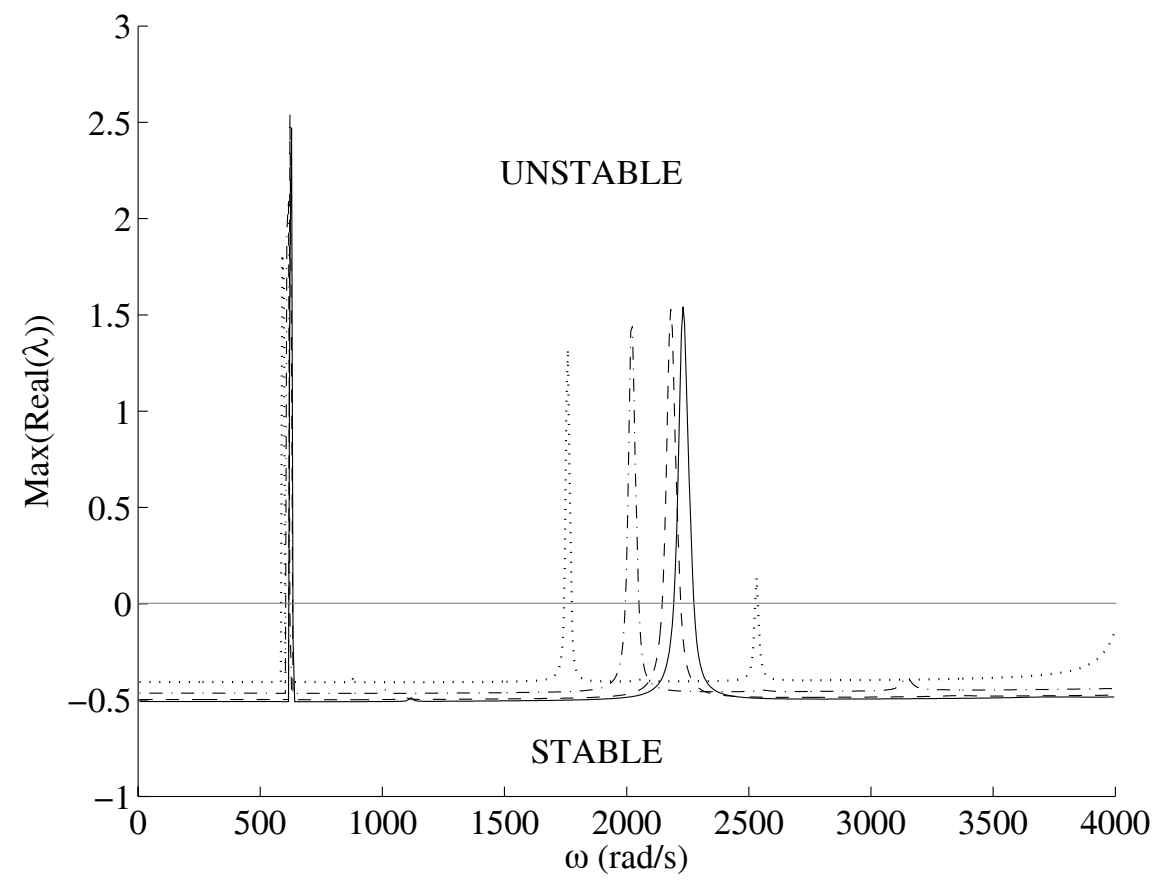

(b) $\mu=1$ and $L_{\text {crack }}=0.175 \mathrm{~m}$

Figure 13: Effects of the supports' stiffness on the main regions of dynamic instability $\left(-K_{s}=\right.$ $210^{7} \mathrm{~N} \cdot \mathrm{m}^{-1},--K_{s}=210^{6} \mathrm{~N} \cdot \mathrm{m}^{-1},-.-K_{s}=510^{5} \mathrm{~N} \cdot \mathrm{m}^{-1}, \ldots K_{s}=210^{5} \mathrm{~N} \cdot \mathrm{m}^{-1}$ ) 


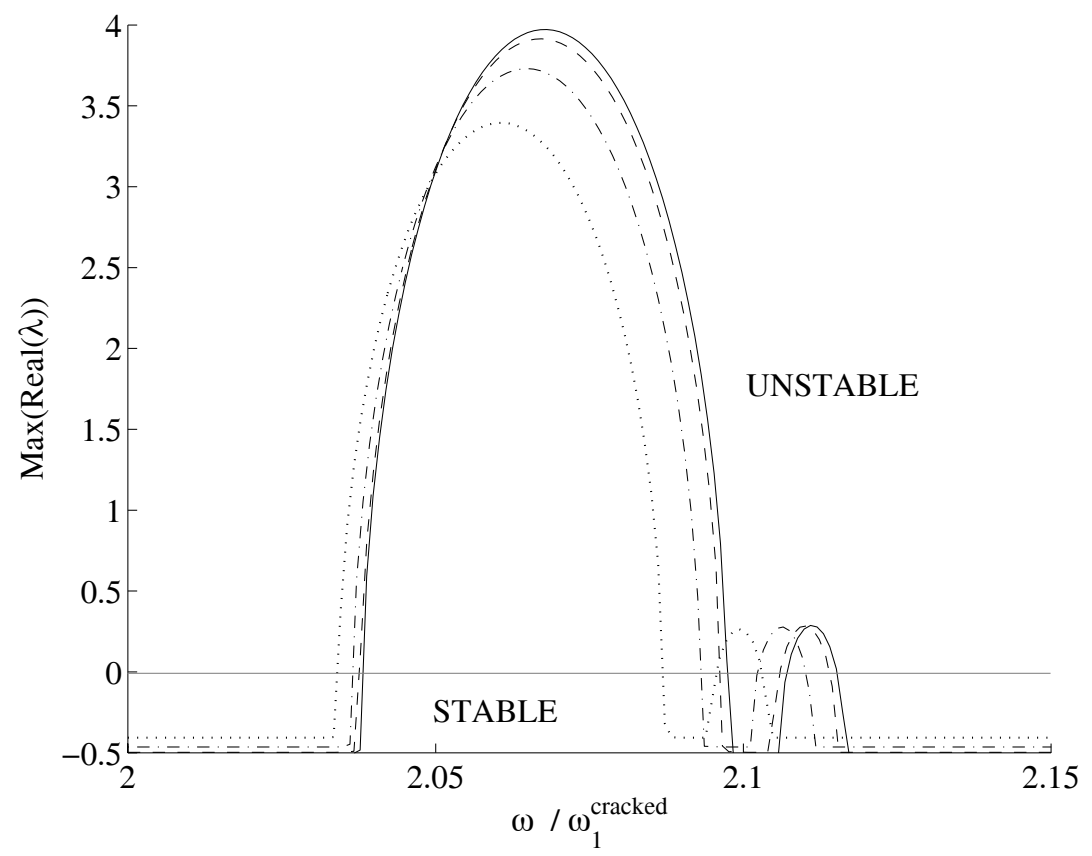

Figure 14: Effects of the supports' stiffness on the first region of dynamic instability for $\mu=1$ and $L_{\text {crack }}=0.225 m\left(-K_{s}=210^{7} N \cdot m^{-1},--K_{s}=210^{6} N \cdot m^{-1},-.-K_{s}=510^{5} N \cdot m^{-1}\right.$, $\left.\ldots K_{s}=210^{5} \mathrm{~N} \cdot \mathrm{m}^{-1}\right)$

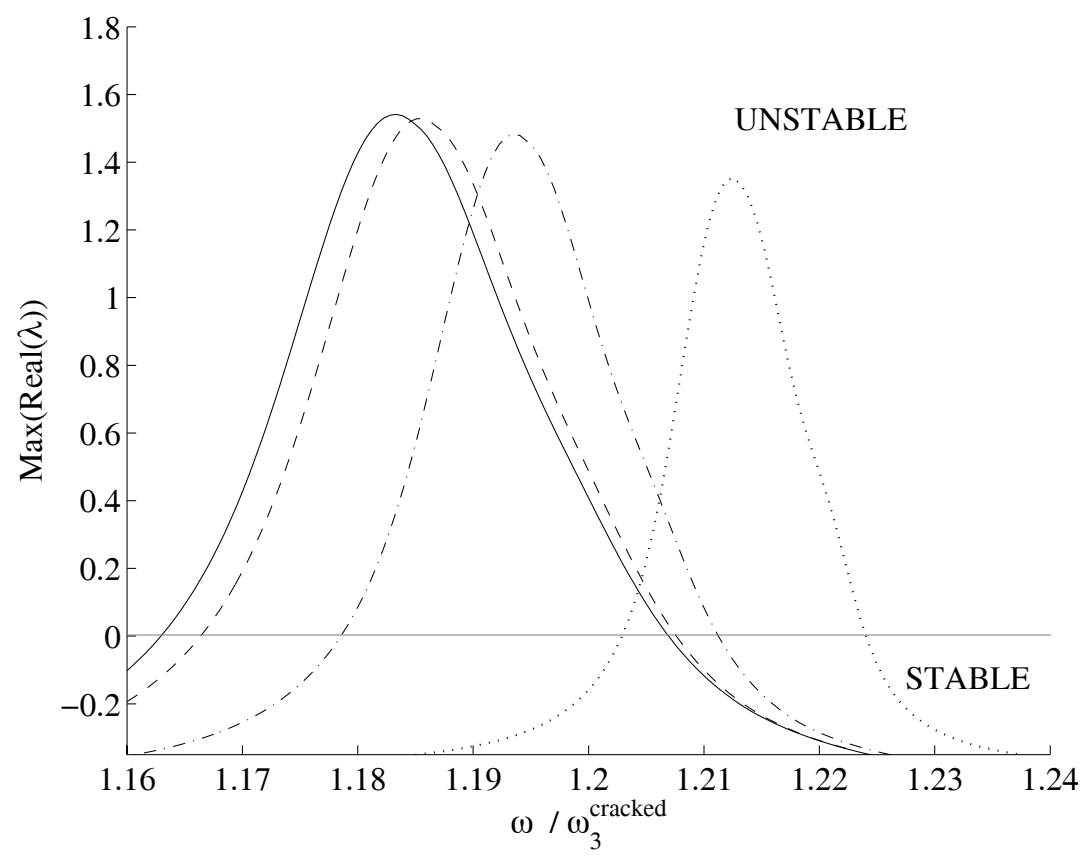

Figure 15: Effects of the supports' stiffness on the second region of dynamic instability for $\mu=1$ and $L_{\text {crack }}=0.175 m\left(-K_{s}=210^{7} N \cdot m^{-1},--K_{s}=210^{6} \mathrm{~N} \cdot \mathrm{m}^{-1},-.-K_{s}=510^{5} \mathrm{~N} \cdot \mathrm{m}^{-1}\right.$, $\left.\ldots K_{s}=210^{5} \mathrm{~N} \cdot \mathrm{m}^{-1}\right)$ 


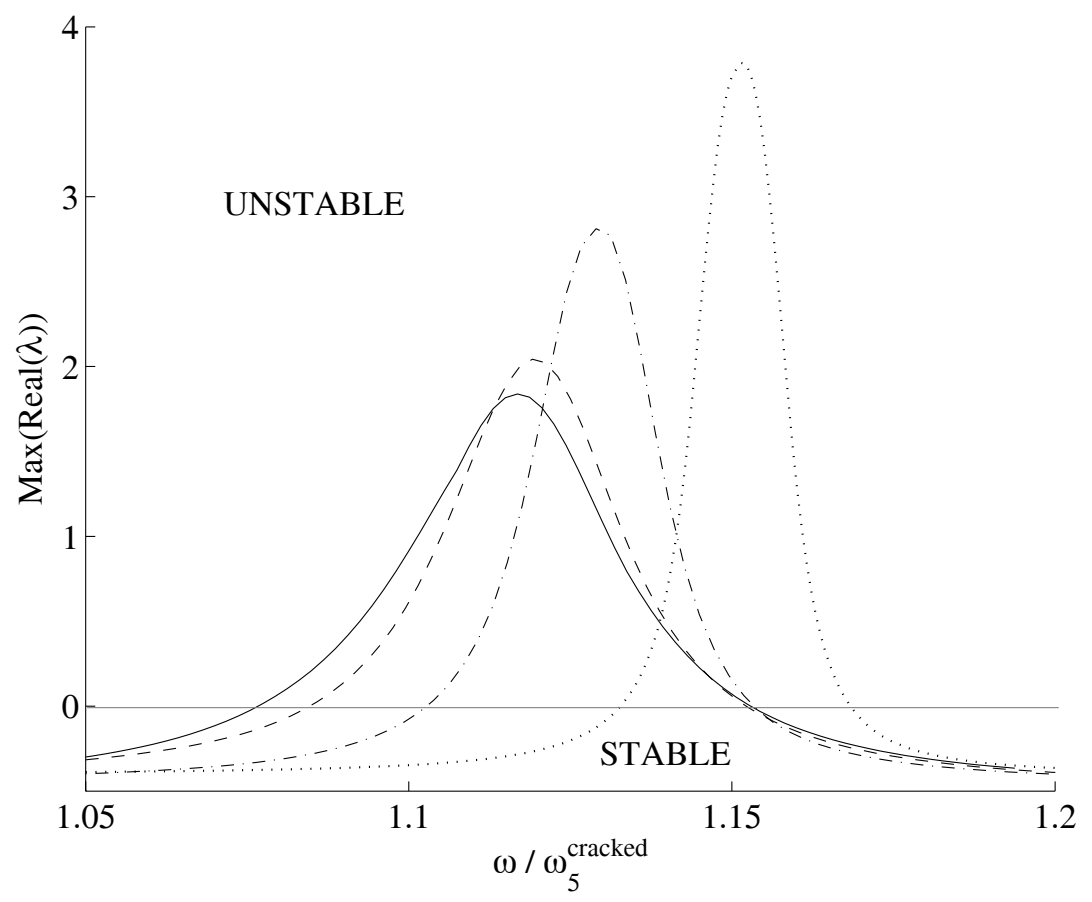

Figure 16: Effects of the supports' stiffness on the third region of dynamic instability for $\mu=1$ and $L_{\text {crack }}=0.225 m\left(-K_{s}=210^{7} N \cdot m^{-1},--K_{s}=210^{6} N \cdot m^{-1},-.-K_{s}=510^{5} \mathrm{~N} \cdot \mathrm{m}^{-1}\right.$, $\left.\ldots K_{s}=210^{5} \mathrm{~N} \cdot \mathrm{m}^{-1}\right)$

\begin{tabular}{cccccccc}
\hline Stiffness $\left(N . m^{-1}\right)$ & & $\omega_{1}$ & $\omega_{2}$ & $\omega_{3}$ & $\omega_{4}$ & $\omega_{5}$ & $\omega_{6}$ \\
\hline $210^{5}$ & & 302 & 302 & 1473 & 1473 & 2239 & 2239 \\
$510^{5}$ & & 312 & 312 & 1735 & 1735 & 2843 & 2843 \\
$210^{6}$ & & 317 & 317 & 1898 & 1898 & 3332 & 3332 \\
$210^{7}$ & & 319 & 319 & 1949 & 1949 & 3493 & 3493 \\
& & & & & & & \\
\hline & $L_{\text {crack }}(m)$ & $\omega_{1}^{\text {cracked }}$ & $\omega_{2}^{\text {cracked }}$ & $\omega_{3}^{\text {cracked }}$ & $\omega_{4}^{\text {cracked }}$ & $\omega_{5}^{\text {cracked }}$ & $\omega_{6}^{\text {cracked }}$ \\
\hline $210^{5}$ & 0.225 & 286 & 299 & 1468 & 1472 & 2176 & 2228 \\
& 0.175 & 291 & 300 & 1450 & 1469 & 2229 & 2238 \\
$510^{5}$ & 0.225 & 295 & 309 & 1725 & 1733 & 2749 & 2826 \\
& 0.175 & 300 & 310 & 1693 & 1727 & 2834 & 2842 \\
$210^{6}$ & 0.225 & 299 & 314 & 1884 & 1895 & 3200 & 3308 \\
& 0.175 & 305 & 315 & 1839 & 1887 & 3319 & 3330 \\
& 0.225 & 301 & 316 & 1934 & 1946 & 3347 & 3466 \\
& 0.175 & 306 & 317 & 1885 & 1938 & 3476 & 3491 \\
\hline
\end{tabular}

Table 3: Values of the uncracked pulsations $\omega_{i}$ and the cracked pulsations $\omega_{i}^{\text {cracked }}$ (in rad.s ${ }^{-1}$ ) of the rotor system versus the supports' stiffness 


\subsubsection{Influence of disk location}

Figure 17 indicates the influence of the disk's location on the main instability zones, for two locations of the crack (the non-dimensional crack $\mu$ is equal to 1 ).

Firstly, it can be observed that the maximum real part of the eigenvalues is slightly affected by the disk position. This is due to the fact that the gyroscopic influence of the disk varies when it is moved along the shaft, from the middle towards the left end of the cracked rotor.

As previously seen, the position of the crack affects the stability of the non-linear periodic solution: Figure 17(a) shows that the second region of instability (between $1900 \mathrm{rad} / \mathrm{s}$ and $2300 \mathrm{rad} / \mathrm{s}$ ) decreases if the crack is closer to the nodal point of the second mode, which is situated at the middle of the rotor. Figure 17(b) shows that the third region of instability (between $3400 \mathrm{rad} / \mathrm{s}$ and $4500 \mathrm{rad} / \mathrm{s}$ ) decreases when the crack approaches the third-way point at the left end of the rotor, where one of the nodal points of the third mode is located.

For each region of dynamic instability, the location of the crack is then chosen in such a way as to obtain the largest area of instability, when the non-dimensional crack depth is equal to 1 . As previously explained, the rotational speed of the cracked rotor is normalized by the $(2 i-1)^{t h}$ pulsation of the associated cracked rotor for the $i^{t h}$ main region of dynamic instability. Table 4 shows how the pulsations of the cracked and uncracked rotor vary as a function of disk location.

Figure 18 illustrates the influence of disk location on the first main region of dynamic instability. It can be seen that the region of dynamic instability is minimized when the disk is located at the middle of the cracked rotor. The region of dynamic instability increases when the disk moves from the middle towards either end of the shaft. However, Figure 18 indicates that the normalized threshold critical speed reaches a minimum when the disk is located at the middle of the shaft.

Figure 19 illustrates the resulting variations in the second main region of dynamic instability: the position of the disk has a significant influence on this region and on the extent of dynamic instability. From this figure, it can be seen that the region of dynamic instability reaches a minimum when the disk is located at the left end of the shaft. The largest unstable region is obtained when the disk is located at one third of the length of the shaft. However, the normalized critical rotation speed reaches its lowest when the disk is positioned at the middle of the shaft.

Figure 20 illustrates the influence of disk location on the third main region of dynamic instability. The minimum normalized threshold speed limit and the largest region of dynamic instability occur when the disk is located towards the left end of the shaft, near to the $\frac{1}{3}$ way point of its total length.

Finally, the cracked rotor system still remains stable at rotational speeds near to $\frac{1}{2} \times$ and $1 \times$ its first critical speed.

In conclusion, the influence of disk's position on the size of the unstable region and on the normalized threshold speed limits appears to be very complex. 


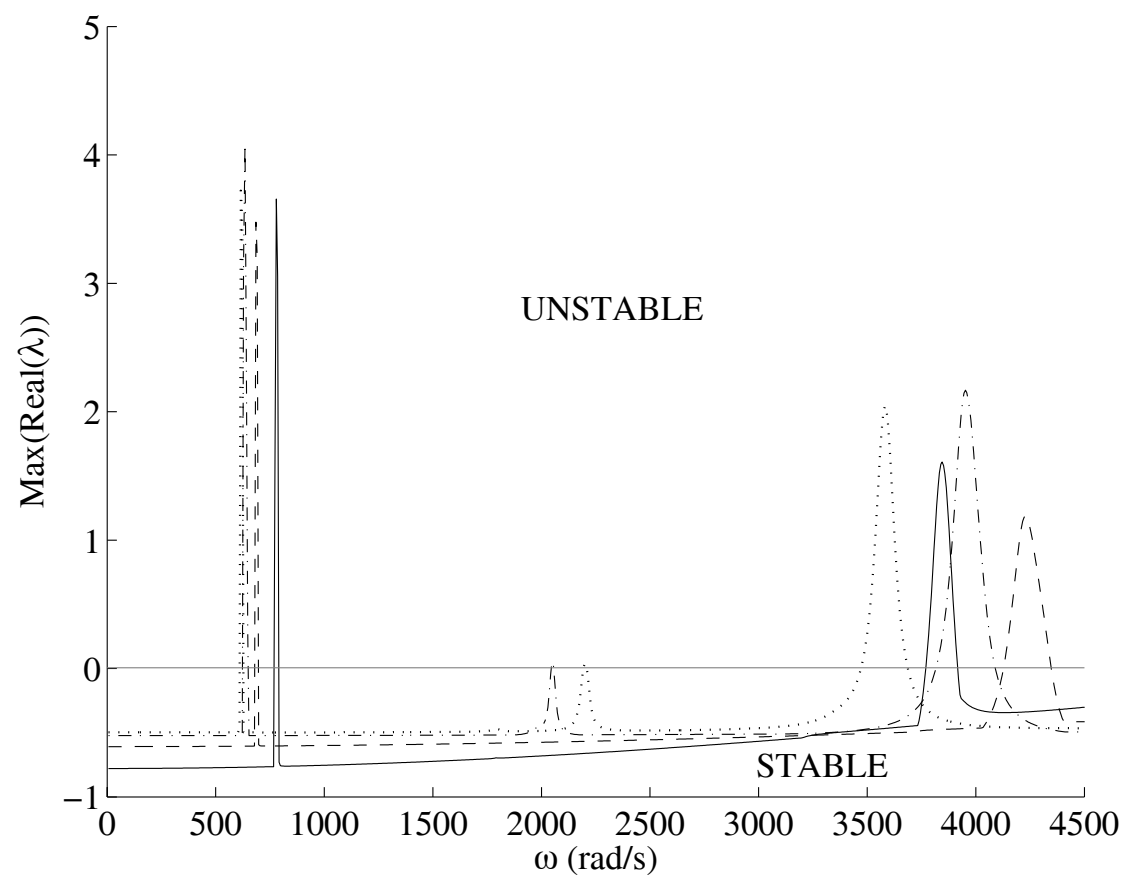

(a) $\mu=1$ and $L_{\text {crack }}=0.225 \mathrm{~m}$

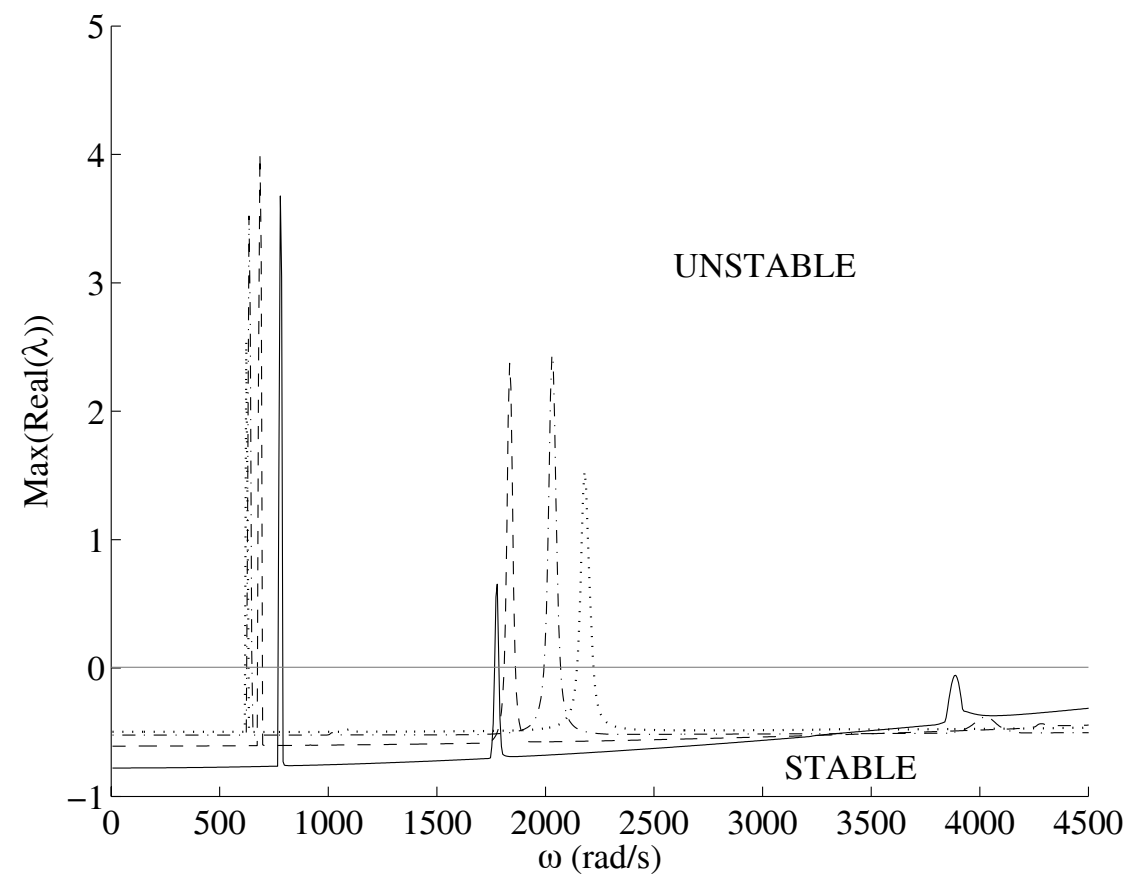

(b) $\mu=1$ and $L_{\text {crack }}=0.175 \mathrm{~m}$

Figure 17: Effects of the disk location on the main regions of dynamic instability $\left(-L_{d}=0.1 \mathrm{~m}\right.$, $-L_{d}=0.15 m,-.-L_{d}=0.2 m, \ldots L_{d}=0.25 m$ ) 


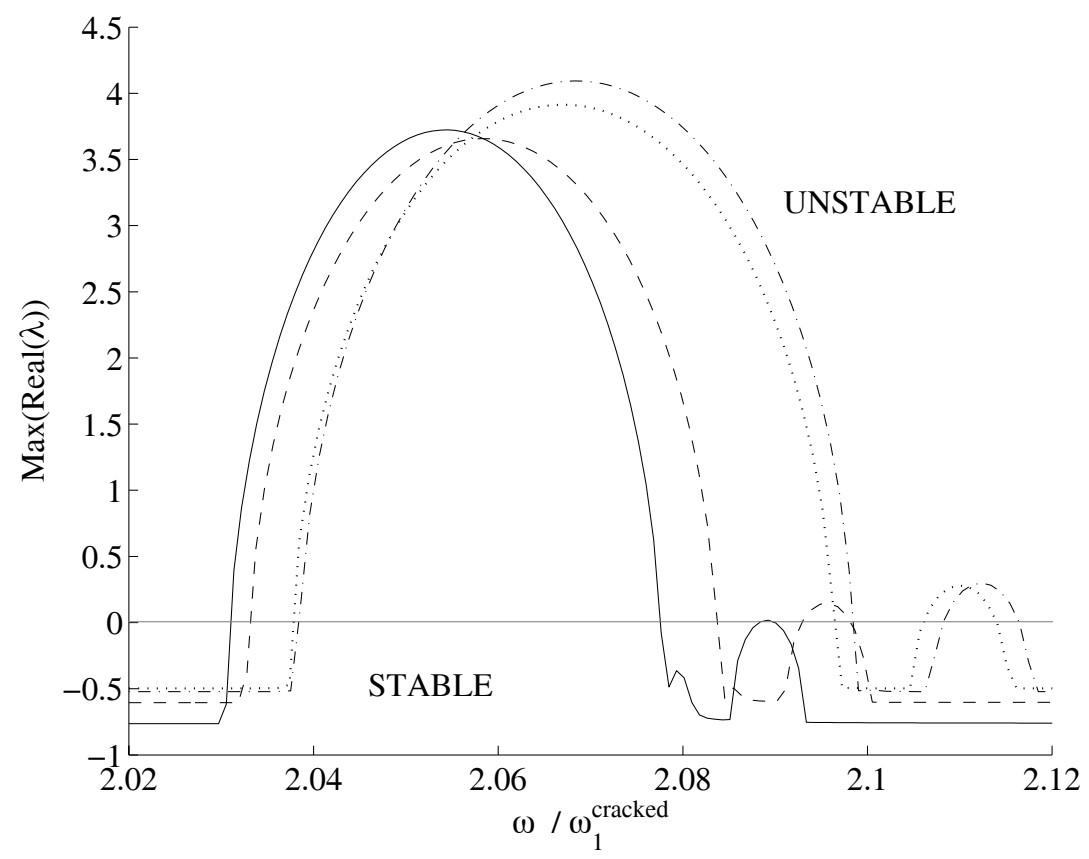

Figure 18: Effects of the disk location on the first region of dynamic instability for $\mu=1$ and $L_{\text {crack }}=$ $0.225 m\left(-L_{d}=0.1 m,--L_{d}=0.15 m,-.-L_{d}=0.2 m, \ldots L_{d}=0.25 m\right)$

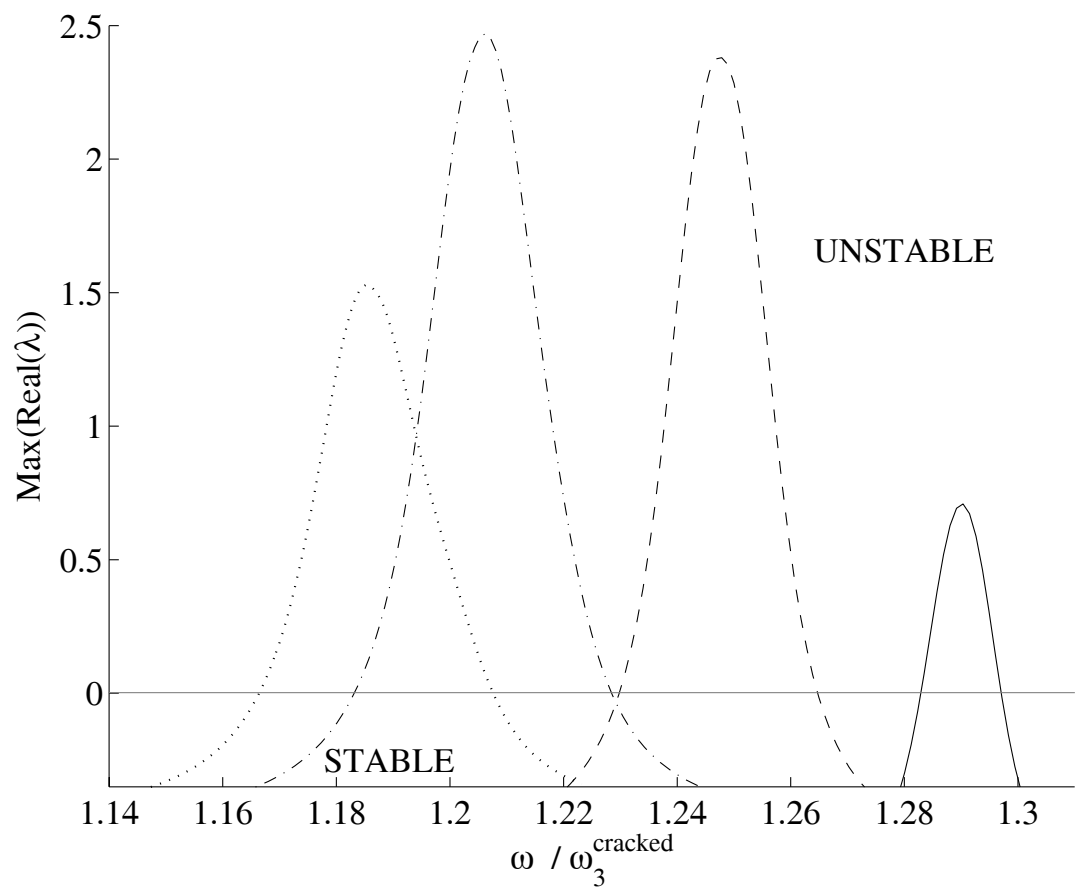

Figure 19: Effects of the disk location on the second region of dynamic instability for $\mu=1$ and $L_{\text {crack }}=0.175 m\left(-L_{d}=0.1 m,--L_{d}=0.15 m,-.-L_{d}=0.2 m, \ldots L_{d}=0.25 m\right)$ 


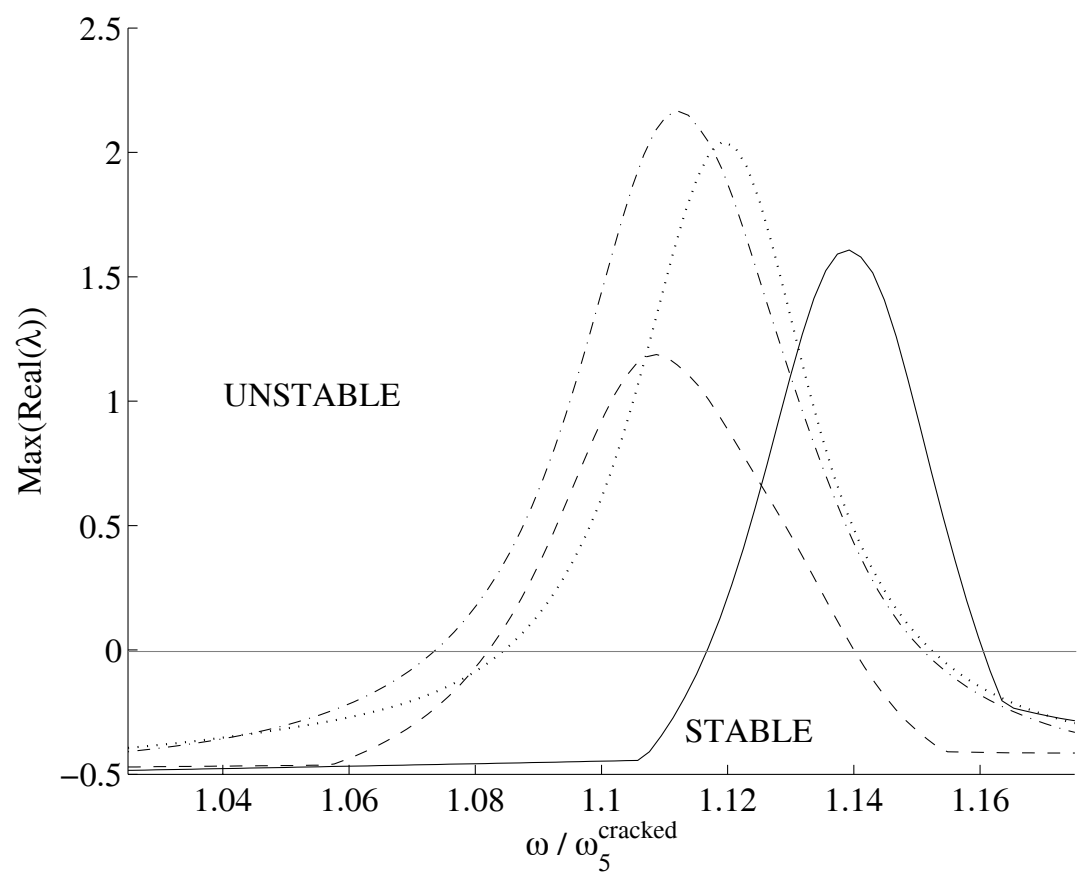

Figure 20: Effects of the disk location on the third region of dynamic instability for $\mu=1$ and $L_{\text {crack }}=$ $0.225 m\left(-L_{d}=0.1 m,--L_{d}=0.15 m,-.-L_{d}=0.2 m, \ldots L_{d}=0.25 m\right)$

\begin{tabular}{cccccccc}
\hline Disk position $(m)$ & & $\omega_{1}$ & $\omega_{2}$ & $\omega_{3}$ & $\omega_{4}$ & $\omega_{5}$ & $\omega_{6}$ \\
\hline 0.25 & & 317 & 317 & 1898 & 1898 & 3332 & 3332 \\
0.2 & & 325 & 325 & 1738 & 1738 & 3716 & 3716 \\
0.15 & & 351 & 351 & 1511 & 1511 & 3968 & 3968 \\
0.1 & & 398 & 398 & 1393 & 1393 & 3526 & 3526 \\
& & & & & & & \\
\hline & $L_{\text {crack }}(m)$ & $\omega_{1}^{\text {cracked }}$ & $\omega_{2}^{\text {cracked }}$ & $\omega_{3}^{\text {cracked }}$ & $\omega_{4}^{\text {cracked }}$ & $\omega_{5}^{\text {cracked }}$ & $\omega_{6}^{\text {cracked }}$ \\
\hline 0.25 & 0.225 & 299 & 314 & 1884 & 1895 & 3200 & 3308 \\
& 0.175 & 299 & 314 & 1884 & 1895 & 3200 & 3308 \\
0.2 & 0.225 & 306 & 322 & 1725 & 1736 & 3554 & 3685 \\
& 0.175 & 309 & 322 & 1685 & 1729 & 3683 & 3710 \\
0.15 & 0.225 & 334 & 348 & 1507 & 1510 & 3814 & 3940 \\
& 0.175 & 332 & 348 & 1472 & 1504 & 3932 & 3962 \\
& 0.225 & 380 & 395 & 1390 & 1393 & 3375 & 3499 \\
& 0.175 & 380 & 395 & 1376 & 1390 & 3460 & 3515 \\
\hline
\end{tabular}

Table 4: Values of the uncracked pulsations $\omega_{i}$ and the cracked pulsations $\omega_{i}^{\text {cracked }}$ (in rad.s ${ }^{-1}$ ) of the rotor system versus the disk position 


\section{Conclusion}

The dynamic characteristics and stability of the non-linear periodic solutions for a cracked rotor are analyzed in this paper. The stability analysis is carried out by applying a perturbation to the non-linear periodic solution, previously computed using the harmonic balance method.

Firstly, the influence of a tranverse crack on the dynamic characteristics of a cracked rotor is discussed. It is demonstrated that the vibrational behaviour of a cracked rotor is complicated by the presence of the $2 \times$ and $3 \times$ resonances of the system response, when the running speed is approximately one-half or one-third of one of the critical speeds. It is shown that the shaft executes respectively two or three loops per shaft revolution, when the rotational speed of the cracked rotor passes through one half or one third of the critical speed.

Secondly, it is shown that the rotor system may in some cases lose its stability when cracks appear. The influence of crack size and location are significant for the main regions of dynamic instability, which expand with the crack increases in depth. Disk location and support stiffness influence the main regions of dynamic instability when cracks appear, whereas flexible rotor supports can reduce both the threshold speed limits and the extent of the regions of instability.

\section{References}

[1] Wauer, J., 1990. "Dynamics of cracked rotors: Literature survey". Applied Mechanics Review, 43, pp. 13-17 .

[2] Dimarogonas, A., 1996. "Vibration of cracked structures: a state of the art review". Engineering Fracture Mechanics, 55, pp. 831-857.

[3] Henry, T., and Okah, B., 1976. "Vibration in cracked shafts". IMechE Conference on Vibrations in Rotating Machinery, C/162/76, p. 15-19.

[4] Gasch, R., 1976. "Dynamic behaviour of a simple rotor with a cross-sectional crack". IMechE Conference on Vibrations in Rotating Machinery, C/178/76, p. 123-128.

[5] Gasch, R., 1993. "A survey of the dynamic behaviour of a simple rotating shaft with a transverse crack". Journal of Sound and Vibration, 160(2), pp. 313-332.

[6] Mayes, I., and Davies, W., 1976. "The vibrational behaviour of a rotatingsystem containinga transverse crack". IMechE Conference on Vibrations in Rotating Machinery, C/168/76, pp. 53-64.

[7] Nelson, H., and Nataraj, C., 1986. "The dynamics of a rotor system with a cracked shaft". Journal of Vibration, Acoustics, Stress and Reliability in Design, 108, p. 189-196.

[8] Wauer, J., 1990. "Modelling and formulation of equations for cracked rotating shafts". Int. J. Solids Structures, 26 (8), p. 901-914.

[9] Tsai, T., and Wang, Y., 1996. "Vibration analysis and diagnosis of a cracked shaft". Journal of Sound and Vibration, 192 (3), p. 607-620.

[10] Sekhar, A., and Prabhu, B., 1998. "Condition monitoring of cracked rotors through transient response". Mechanism and Machine Theory, 33 (8), p. 1167-1175.

[11] Friswell, M., and Penny, J., 2002. "Crack modelling for structural health monitoring”. International Journal of Structural Health Monitoring, 1 (2), p. 139-148. 
[12] Darpe, A., Chawla, A., and Gupta, K., 2002. "Analysis of the response of a cracked jeffcott rotor to axial excitation". Journal of Sound and Vibration, 249(3), p. 429-445.

[13] Adewusi, S., and Al-Bedoor, B., 2002. "Experimental study on the vibration of an overhung rotor with a propagating transverse crack". Shock and Vibration, 9, p. 91-104.

[14] Sinou, J.-J., and Lees, A. W., 2005. "Influence of cracks in rotating shafts". Journal of Sound and Vibration, 285(4-5), pp. 1015-1037.

[15] Sinou, J.-J., and Lees, A. W., 2007. "A non-linear study of a cracked rotor". European Journal of Mechanics A/Solids, 26(1), pp. 152-170.

[16] Papadopoulos, C., and Dimarogonas, A., 1988. "Stability of cracked rotors in the coupled vibration mode”. Journal of Vibration, Acoustics, Stress, and Reliability in Design, 110, p. 357-359.

[17] Jun, O., Eun, H., and Lee, Y. E. C., 1992. "Modelling and vibration analysis of a simple rotor with a breathing crack". Journal of Sound and Vibration, 155 (2), p. 273-290.

[18] Huang, S., Huang, Y., and Shieh, S., 1993. "Vibration and stability of a rotating shaft containing a transverse crack". Journal of Sound and Vibration, 162 (3), p. 387-401.

[19] Chen, L., and Peng, W., 1998. "Dynamic stability of rotating composite shafts under periodic axial compressive loads". Journal of Sound and Vibration, 212(2), p. 215-230.

[20] Meng, G., and Gasch, R., 2000. "Stability and stability degree of a cracked flexible rotor supported on journal bearings". Journal of Vibration and Acoustics, 122, pp. 116-125.

[21] Sekhar, A., and Dey, J., 2000. "Effects of cracks on rotor system instability". Mechanism and Machine Theory, 35, p. 1657-1674.

[22] Zhu, C., Robb, D., and Ewins, D., 2003. "The dynamics of a cracked rotor with an active magnetic bearing". Journal of Sound and Vibration, 265, p. 469-487.

[23] Chen, C., Dai, L., and Fu, Y., 2006. "Nonlinear response and dynamic stability of a cracked rotor". Communications in Nonlinear Science and Numerical Simulation, In press, p. 15.

[24] Davies, W. G. R., and Mayes, I. W., 1984. "The vibrational behaviour of a multi-shaft, multibearing system in the presence of a propagating transverse crack". Transactions of the ASME Journal of Vibration, Acoustics, Stress, and Reliability in Design, 106, pp. 146-153.

[25] Mayes, I. W., and Davies, W. G. R., 1984. "Analysis of the response of a multi-rotor-bearing system containing a transverse crack in a rotor". Transactions of the ASME Journal of Vibration, Acoustics, Stress, and Reliability in Design, 106, pp. 139-145.

[26] Nayfeh, A., and Balachandran, B., 1995. Applied nonlinear dynamics : analytical, computational and experimental methods. John Wiley \& Sons.

[27] He, J., 2006. "Some asymptotic methods for strongly nonlinear equations". International Journal of Modern Physics B, 20(10), pp. 1141-1199.

[28] Sinou, J.-J., Thouverez, F., and Jézéquel, L., 2004. "Methods to reduce non-linear mechanical systems for instability computation". Archives of Computational Methods in Engineering: State of the Art Reviews, 11(3), pp. 257-344. 
[29] Cameron, T. M., and Griffin, J. H., 1989. "An alternating frequency time domain method for calculating the steady state response of nonlinear dynamic systems". ASME Journal of Applied Mechanics, 56, pp. 149-154.

[30] Cardona, A., Lerusse, A., and Geradin, M., 1998. "Fast fourier nonlinear vibration analysis". Computational Mechanics, 22, pp. 128-142.

[31] Groll, G., and Ewins, D. J., 2001. "The harmonic balance method with arc-length continuation in rotor/stator contact problems". Journal of Sound and Vibration, 241(2), pp. 223-233. 